\title{
Mucosal-associated invariant T cells and disease
}

Amine Toubal ${ }^{1,2,3}$, Isabelle Nel ${ }^{1,2,3}$, Sophie Lotersztajn ${ }^{2,3,4}$ and Agnès Lehuen (1) ${ }^{1,2,3 *}$

Abstract | Mucosal-associated invariant T (MAIT) cells are unique innate-like T cells that bridge innate and adaptive immunity. They are activated by conserved bacterial ligands derived from vitamin $B$ biosynthesis and have important roles in defence against bacterial and viral infections. However, they can also have various deleterious and protective functions in autoimmune, inflammatory and metabolic diseases. MAIT cell involvement in a large spectrum of pathological conditions makes them attractive targets for potential therapeutic approaches.

The immune system is traditionally divided into the adaptive and innate arms that together mount efficient immune responses against invading pathogens and preserve body integrity. Conventional $\mathrm{T}$ and $\mathrm{B}$ cells of the adaptive immune system induce specific responses and provide long-term memory against microorganisms, whereas the innate immune system allows immediate recognition of pathogens and moulds adaptive immune responses. Mucosal-associated invariant T (MAIT) cells are innate-like $\mathrm{T}$ cells and thus can be considered to span both the innate and adaptive arms. They were originally identified on the basis of expression of an invariant T cell receptor (TCR) a-chain (Va7.2-Ja33 in humans, and Va19-Ja33 in mice) associated with a limited TCR $\beta$-chain repertoire ${ }^{1-3}$. In 2003, Lantz and colleagues showed that MAIT cells are restricted by the non-polymorphic MHC class I-related (MR1) molecule, which is highly conserved in mammals and expressed by most cell types ${ }^{3}$. Subsequent studies revealed the antibacterial recognition and function of MAIT cells $s^{4-7}$. A critical advance in the biology of MAIT cells was the discovery by Rossjohn and McCluskey of the main bacterial ligands presented by the MR1 molecule to MAIT cells, namely agonist ligands derived from the microbial vitamin $B_{2}$ (riboflavin) biosynthesis pathway and modified by the bacterial and host cell metabolites glyoxal and methylglyoxal, as well as non-activating ligands derived from vitamin $\mathrm{B}_{9}$ (folate) ${ }^{8-10}$ (BOX 1). The recent generation of a $\mathrm{V} \alpha 7.2$-specific monoclonal antibody and MR1 tetramers has allowed MAIT cell characterization in both humans and mice. Although MAIT cells were first described as being enriched in mucosal tissues such as those of the intestinal tract and lungs, they are also abundant in the blood and are present in several peripheral tissues in physiological conditions ${ }^{11-19}$ (TABLE 1). The highest frequency of MAIT cells is found in the liver, whereas they are less frequent in lymphoid organs. MAIT cells are more abundant in humans (comprising
$1-35 \%$ of total $\alpha \beta$ T cells) than in common laboratory mouse strains (comprising $0.01-5 \%$ of $\alpha \beta \mathrm{T}$ cells) ${ }^{4,20}$.

These innate-like $\mathrm{T}$ cells exhibit an effector-memory phenotype and are usually characterized in humans by high expression of the C-type lectin CD161. They produce a wide range of cytokines and molecules that induce cytotoxic responses, such as granzyme B and perforin, upon activation through their TCRs and/or cytokine receptors, and they express integrins and chemokine receptors, allowing their migration to inflamed tissues $^{21-23}$. Due to their localization and function, MAIT cells can act as a first line of defence against infections, but they may also contribute to autoimmune and immune-mediated diseases. Unlike existing Reviews $^{23-32}$, we highlight the pathophysiological roles of MAIT cells, emphasizing the common and distinct features of MAIT cells in various pathologies. We address the behaviour of MAIT cells in infectious and non-infectious pathologies and describe their homeostasis, activation, tissue migration, apoptosis and different effector functions through which they can exert protective or deleterious roles.

\section{MAIT cells in infectious diseases}

MR1-dependent MAIT cell activation in bacterial infection. The first functional studies of MAIT cells showed that they are activated by certain bacteria and yeast in an MR1-dependent manner ${ }^{7,33,34}$. Subsequent analyses characterized MAIT cell agonist ligands as metabolites derived from the bacterial vitamin $B_{2}$ synthesis pathway $^{8-10}$ that can be produced by both commensal and pathogenic strains ${ }^{3,35}$. Vitamin $B_{2}$ biosynthesis pathways that are unique to yeast and bacteria allow MAIT cells to sense infection by recognition of conserved microbial metabolites. In patients with Mycobacterium tuberculosis infection, MAIT cells are decreased in the blood but seem to accumulate in the lungs, suggesting that they are recruited to the infected tissues and can 


\section{Box 1 | MAIT cell ligands}

The main ligands for MHC class I-related (MR1) molecules are small organic metabolites derived from two vitamin $B$ sources: metabolites that can activate mucosal-associated invariant T (MAIT) cells are derived from riboflavin (vitamin $B_{2}$ ), and non-stimulatory metabolites are derived from folic acid (vitamin $\left.\mathrm{B}_{9}\right)^{8-10}$. Riboflavin is synthesized by many bacteria and yeasts, but not by mammals. The first described ligands - 7-hydroxy6-methyl-8-D-ribityllumazine and 6,7-dimethyl-8-D-ribityllumazine - can stimulate MAIT cells when presented by MR1, due to the presence of a ribityl tail in their structure that interacts with the MAIT cell T cell receptor. Two single-ring pyrimidine compounds, 5-(2-oxopropylideneamino)-6-D-ribitylaminouracil and 5-(2-oxoethylideneamino)-6D-ribitylaminouracil, which are formed from the spontaneous reaction of the riboflavin precursor 5-amino-6-D-ribitylaminouracil with methylglyoxal or glyoxal, respectively, and are by-products of both bacteria and host cell glycolysis, were recently described as the most potent MAIT cell-activating ligands. 6-Formylpterin and acetyl-6formylpterin, the resulting products of folic acid photodegradation, can both bind to MR1, increasing its stability and its surface expression. These two formylpterins inhibit MAIT cell activation by competing with the activating ligands.

Due to its high structural plasticity, the MR1 pocket can present a large variety of ligands, such as drugs and drug-related molecules with diverse chemical structures ${ }^{110}$. As an example, MR1 can present chemical agonists such as diclofenac or 5-hydroxy diclofenac, as well as chemical inhibitors such as 3-formylsalisylic acid, 5-formylsalisylic acid and 2,4-diamino-6-formylpteridine.

Endogenous mammalian ligands have not yet been identified; however, their existence is likely. MAIT cells are selected in the thymus in an MR1-dependent manner, and this thymic education is maintained in germ-free mice ${ }^{3,35}$. Several in vitro studies also support the presence of endogenous MR1 ligands leading to MAIT cell interaction with hepatic myofibroblasts or tumour cells in an MR1-dependent way in the absence of exogenous ligands $\mathbf{s}^{6,148}$. of patients with bacterial sepsis who exhibit higher frequencies of circulating MAIT cells ${ }^{42}$.

Although studies of the frequency, phenotype and activation status of MAIT cells in patients bring some insight into their function in bacterial infections, most studies are limited to analysis of the blood. The most convincing data supporting the protective role of MAIT cells in bacterial infections have been obtained in mouse models. MAIT cells in mice are exclusively identified by mouse MR1 tetramers, owing to a lack of specific antibodies recognizing the invariant TCR Va19-Ja33 chain. Despite the low frequency of MAIT cells in mice compared with humans (TABLE 1), mouse studies showed that MAIT cells have protective roles against infection by Mycobacterium abscessus, Mycobacterium bovis, E. coli, Klebsiella pneumoniae, Francisella tularensis and Legionella longbeachae ${ }^{6,7,43-47}$. For example, intraperitoneal injection of $E$. coli or $M$. abscessus in $\mathrm{MrI}^{-/-}$mice, which are thereby devoid of MAIT cells, results in a higher bacterial load in the spleen than in MAIT cellcontaining control mice. Intranasal infections of wildtype mice with F. tularensis, M. bovis, S. Typhimurium or L. longbeachae induce an accumulation of MAIT cells in the lungs, where they produce large amounts of cytokines such as IL-17A, IFN $\gamma$ and TNF, depending on the type of infection ${ }^{43,45,47,48}$. MAIT cell accumulation in the lungs after $S$. Typhimurium infection is MR1 dependent and requires the presence of ligands derived from the microbial riboflavin synthesis pathway ${ }^{48}$.

contribute to immune defence ${ }^{5,7,36}$. Functional in vitro studies of MAIT cells from healthy individuals show that they produce interferon- $\gamma$ (IFN $\gamma)$ and tumour necrosis factor (TNF) upon MR1-dependent activation by lung epithelial cells infected with $M$. tuberculosis ${ }^{5,7}$, thereby inducing their death. Interestingly, IFN $\gamma$ production by MAIT cells could be one mechanism by which they control $M$. tuberculosis infection, as IFN $\gamma$ is known to induce antimicrobial mechanisms such as autophagy ${ }^{37}$ and the activation of nitric oxide synthase 2 (NOS2) $)^{38,39}$.

The activation of MAIT cells and their ability to kill infected cells have been confirmed in infection of epithelial cells by various bacteria, such as Escherichia coli and Shigella flexneri ${ }^{33}$. Migration of blood MAIT cells to infected tissue is also suggested in patients who developed typhoid fever after being challenged with oral Salmonella enterica subsp. enterica serovar Typhimurium. These patients have decreased blood MAIT cell frequency compared with those who are resistant to the infection, and their remaining MAIT cells are activated and express high levels of gut-homing chemokine receptors (CCR9 and CCR6), which could allow their migration to the infected intestinal tract ${ }^{40}$. However, the decreased blood MAIT cell frequency could also reflect their activation-induced cell death. In addition to migration, proliferation can also lead to MAIT cell expansion in infected tissue. Indeed, nonhuman primates vaccinated intradermally with bacillus Calmette-Guérin and challenged with pulmonary M. tuberculosis exhibit a higher frequency of proliferating $\left(\mathrm{Ki}-67^{+}\right)$MAIT cells at the site of vaccination ${ }^{41}$. A protective role for MAIT cells against bacterial infections in humans is suggested by the better outcome
MR1-independent activation of MAIT cells. TCRindependent activation of MAIT cells has also emerged as an important mechanism against both bacterial and viral infection (FIG. 1). MAIT cells express high levels of IL-18 receptor (IL-18R) and IL-12R, and IL-18 and IL-12 have emerged as the major cytokines that activate MAIT cells upon bacterial or viral infection ${ }^{43,45,49-68}$ (TABLE 2). During bacterial infection, blockade or deletion of the IL-12p40 subunit impairs MAIT cell control of intracellular growth of $F$. tularensis and M. bovis ${ }^{43,45}$. The effect of IL-18 on MAIT cells in bacterial infection is more uncertain. In vitro studies have shown that F. tularensis and Enterococcus faecalis, whether or not they produce riboflavin, are able to stimulate the production of IFN $\gamma$ by MAIT cells in an IL-12- and/or IL-18dependent manner ${ }^{49,50}$. Furthermore, peripheral blood mononuclear cells or the THP1 monocytic cell line exposed to E. coli (riboflavin-synthesizing) or E. faecalis (non-riboflavin-synthesizing) produce IL-12 and IL-18 via a Toll-like receptor 8 (TLR8) pathway, and both cytokines are required for MAIT cell activation ${ }^{59}$. However, a recent study showed that although IL-18 is required for MAIT cell activation by $F$. tularensis in vitro, this cytokine is not essential for MAIT cell IFN $\gamma$ production in in vivo infection ${ }^{49}$. Bacterial infection in vivo might induce MAIT cell activation through a more complex immune cell crosstalk, involving TLRs expressed by antigen-presenting cells (APCs) ${ }^{48,59}$. Interestingly, cytokine-dependent MAIT cell activation by tissue macrophages or dendritic cells has a key role in the recruitment and differentiation of monocytes in the lungs of infected mice and thereby promotes local $\mathrm{CD} 4^{+}$ 
Table 1 | Features of MAIT cells in humans and mice

\begin{tabular}{|c|c|c|c|c|}
\hline Feature & Human MAIT cells & Refs & Mouse MAIT cells & Refs \\
\hline \multirow[t]{2}{*}{ T cell receptor expression } & Va7.2-Ja33 & 2,20 & Va19-Ja33 & 2,115 \\
\hline & $V \beta 2, V \beta 13$ & 2,20 & $\mathrm{~V} \beta 8.1, \mathrm{~V} \beta 8.2, \mathrm{~V} \beta 6$ & 2,115 \\
\hline $\begin{array}{l}\text { Activation and/or maturation } \\
\text { marker expression }\end{array}$ & $\begin{array}{l}\text { CD69, CD25, CD161, CD95, CD62L low, } \\
\text { CD45RO, CD27 }\end{array}$ & 20,113 & CD69, CD25, CD38, CD62L, CD44 & $69,70,115$ \\
\hline Cytokine receptor expression & IL-7R, IL-12R, IL-15R, IL-18R, IFNAR & 28,50 & IL-7R, IL-12R, IL-15R, IL-18R & 115 \\
\hline $\begin{array}{l}\text { Chemokine receptor } \\
\text { expression }\end{array}$ & $\begin{array}{l}\text { CCR2, CCR5, CCR6, CCR9, CCR10, CXCR3, } \\
\text { CX }{ }_{3} \text { CR1, CXCR6 }\end{array}$ & 70,152 & $\begin{array}{l}\text { CCR2, CCR5, CCR6, CCR9, CXCR3, } \\
\text { CXCR6 }\end{array}$ & 115 \\
\hline $\begin{array}{l}\text { Natural killer cell and adhesion } \\
\text { marker expression }\end{array}$ & $\begin{array}{l}\text { PD-1, NKG2D, NKP80, NKP30, aL integrin, } \\
\text { CD56, CD43, CD49a, CD103, CLA, a } 4 \beta 1 \\
\text { integrin, PSGL1, sLex }\end{array}$ & $18,70,91,98,113,153-156$ & NK1.1 & 115 \\
\hline
\end{tabular}

T cell recruitment and activation ${ }^{46}$. These studies highlight the ability of MAIT cells to bridge the innate and adaptive arms of an immune response.

During viral infection, MAIT cells are also activated by cytokines produced by dendritic cells or macrophages. Of note, unlike bacteria, viruses are unable to generate riboflavin-derived ligands to activate MAIT cells. In vitro, myeloid cells exposed to hepatitis C virus ( $\mathrm{HCV}$ ), dengue virus and influenza virus activate MAIT cells to produce IFN $\gamma$, TNF and granzyme B in an IL-18-dependent manner, which might act in synergy with IL-12, IL-15 and type I interferons ${ }^{62,66}$. Through the production of IFN $\gamma$, TNF and granzyme B, MAIT cells inhibit viral replication and may exert cytotoxic function against virus-infected cells. In patients with acute viral infection by dengue or influenza virus, MAIT cells rapidly acquire an activated phenotype characterized by the expression of activation and exhaustion markers such as CD38, CD69, PD-1 and TIM3 (REFS ${ }^{62,63,66}$ ). Moreover, there is a positive association between the frequency of activated blood MAIT cells and the severity of dengue disease $^{66}$, which could be due to higher viral load and/or inflammatory cytokine levels. Although patients with dengue infection have frequencies of circulating MAIT cells similar to those in healthy controls, circulating MAIT cells are reduced in patients with influenza virus infection. Accumulation of MAIT cells in the lungs of mice infected with influenza virus suggests their recruitment from the blood to infected sites, and this was associated with their increased expression of activation markers such as CD69 and CD25 and increased production of granzyme $\mathrm{B}^{62,66}$. Analysis of MR1-deficient mice and transfer of MAIT cells demonstrated a protective role for MAIT cells in this infection ${ }^{67}$.
In chronic infections by hepatitis B virus (HBV), $\mathrm{HCV}$ and HIV, most studies have described a decrease in MAIT cell numbers both in the blood and in tissues such as the liver. Despite their reduction in frequency and defective in vitro response to $E$. coli, the ability of MAIT cells to respond to IL-12 or IL-18 is generally preserved $^{51-58,60,66,68}$. Indeed, as has been observed in dengue and influenza virus infections, the remaining MAIT cells express higher levels of activation and/or exhaustion markers, such as CD38, HLA-DR, CD69 and PD-1, and produce IFN $\gamma$ and granzyme $\mathrm{B}$ on activation.

However, some human studies have described a functional impairment of MAIT cells in chronic $\mathrm{HBV}^{68}$ and $\mathrm{HIV}^{60,61}$ infection, with decreased IFN $\gamma$, TNF and IL-17A production and reduced cytotoxicity, after in vitro TCR-dependent activation, correlating with very low levels of expression of the transcription factors T-bet, EOMES, PLZF, ROR $\gamma \mathrm{t}$ and HELIOS ${ }^{61}$. In a small cohort of HIV-infected patients, treatment with recombinant human IL-7 restored the frequency of circulating MAIT cells, as was previously shown for conventional $\mathrm{CD}^{+}$and $\mathrm{CD}^{+} \mathrm{T}$ cells ${ }^{64}$, and functional analysis of one treated patient showed that MAIT cell responsiveness to IL-12 and/or IL-18 or E. coli stimulation was also restored ${ }^{65}$.

Overall, studies in vitro, in mouse models and in patients demonstrate the ability of MAIT cells to sense bacterial and viral infection. The protective role of MAIT cells in several infections, such as tuberculosis and influenza virus, suggests that therapeutic approaches based on the activation of MAIT cells by cytokines and/or agonist ligands could be developed. By contrast, the potential deleterious role of MAIT cells in other infections, such as dengue, warrants further investigation. 
a MR1-dependent activation

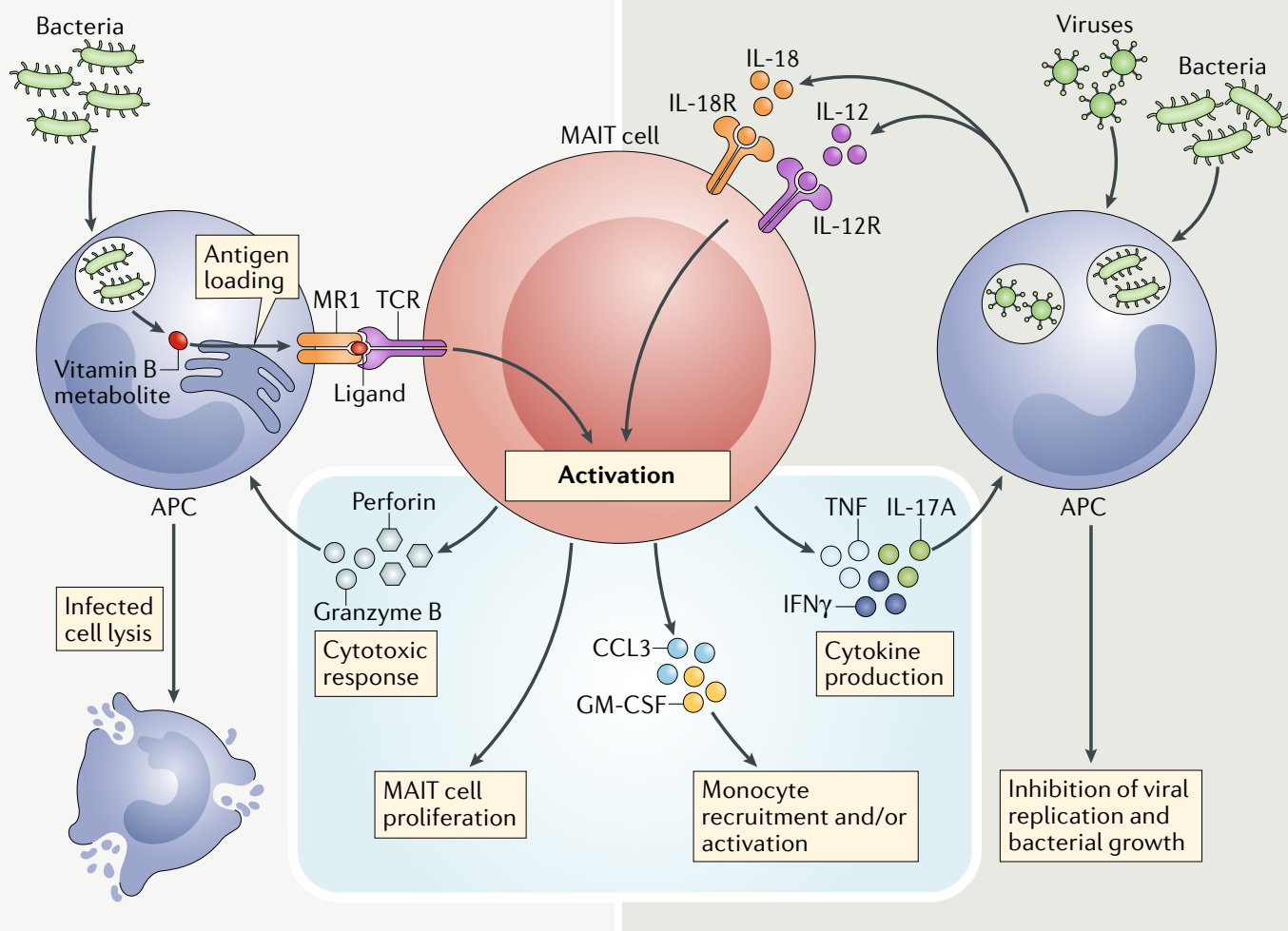

Fig. 1 | MAIT cell activation in bacterial and viral infection. Upon bacterial and viral infections, mucosal-associated invariant T (MAIT) cells can be activated in a MHC class I-related molecule (MR1)-dependent manner through their T cell receptor (TCR) recognizing MR1-presenting bacterial ligands (part a), and/or in an MR1-independent manner by inflammatory cytokines such as IL-12 and IL-18, produced by infected cells and sensed by MAIT cells through cytokine receptors (part b). MAIT cell activation induces their release of granzyme B and perforin (which kill infected cells), their proliferation and their production of cytokines (tumour necrosis factor (TNF), interferon- $\gamma$ (IFN $\gamma$ ) and IL-17A) that inhibit viral replication and bacterial growth. Activated MAIT cells can also promote monocyte recruitment and activation. APC, antigen-presenting cell; CCL3, CC-chemokine ligand 3; GM-CSF, granulocyte-macrophage colony-stimulating factor; IL-12R, IL-12 receptor.

\section{MAIT cells in immune-mediated diseases}

MAIT cell characteristics (TABLE 1) - including activation by inflammatory cytokines, expression of chemokine receptors and integrins, and the production of large amounts of cytokines and cytotoxic molecules suggest that MAIT cells, similarly to conventional effector memory $\mathrm{T}$ cells, could be involved in autoimmune and immune-mediated chronic diseases. However, in contrast to conventional T cells, circulating MAIT cells can function without specific antigen priming and following antigen-nonspecific activation by cytokines produced in an inflammatory context. In addition, inflammation increases the surface expression of MR1 protein $^{69-71}$, suggesting that MAIT cells could be activated through their TCRs following recognition of MR1 molecules presenting bacterial, or possibly endogenous, ligands (BOX 1). After activation, MAIT cells could act directly on target cells or could participate to the recruitment and activation of other immune cells, as in infectious diseases. Numerous reports have described MAIT cell alterations in patients with various autoimmune and immune-mediated pathologies. Despite the heterogeneity of the disease aetiologies, there are several common features, such as reduced MAIT cell frequency in the blood, their presence in the target tissue and their increased activation and dysfunction.

Decreased circulating MAIT cell frequency. As reported in chronic infectious diseases, the number of circulating MAIT cells decreases in most autoimmune diseases and in many inflammatory and metabolic diseases ${ }^{16,18,24,69,70,72-86}$ (FIG. 2; TABLE 3). Blood MAIT cell frequency correlates with disease severity in several pathologies $^{87-94}$ (TABLE 3). In multiple sclerosis (MS), the frequency of blood MAIT cells decreases during clinical relapse and progression of the disease, whereas it increases during remission ${ }^{71,95}$. Similarly, after bariatric surgery, obese patients improve in their metabolic and inflammatory parameters, simultaneously increasing in their number of blood MAIT cells ${ }^{16}$. Only a few studies have characterized circulating MAIT cell subsets according to their CD4 or CD8 expression in autoimmune and inflammatory diseases. In humans, MAIT cells are mainly CD8 positive, approximately $10 \%$ are CD 4 and CD8 double negative, and very few are CD4 positive. When MAIT cell subsets are characterized, the frequencies of both $\mathrm{CD}^{+}{ }^{+}$and $\mathrm{CD} 4^{-} \mathrm{CD} 8^{-}$circulating MAIT cells are similarly decreased ${ }^{18,70,80,87,94}$. The very low frequency 
Table 2 | MAIT cells in infectious diseases

\begin{tabular}{|c|c|c|c|c|}
\hline $\begin{array}{l}\text { Infectious } \\
\text { disease }\end{array}$ & $\begin{array}{l}\text { MAIT cell } \\
\text { frequency }\end{array}$ & MAIT cell phenotype & MAIT cell function & Refs \\
\hline \multicolumn{5}{|c|}{ Bacterial infection } \\
\hline Legionella & $\uparrow$ in lungs & ND & $\uparrow I F N \gamma$ and $G M-C S F$ & 47 \\
\hline Tuberculosis & $\begin{array}{l}\downarrow \text { in blood; } \uparrow \text { in } \\
\text { lungs }\end{array}$ & $\uparrow$ PD-1 in blood & $\uparrow I \mathrm{IL}-17 \mathrm{~A}$ and granzyme $\mathrm{B}$ & $5,7,36,157$ \\
\hline Shigellosis & $\downarrow$ in blood & $\uparrow$ Activation markers? & ND & 33 \\
\hline Klebsiella & ND & ND & $\downarrow$ Bacterial load in vivo & 6 \\
\hline \multicolumn{5}{|l|}{ Viral infection } \\
\hline Influenza & $\downarrow$ in blood & $\uparrow \mathrm{CD} 25$ and CD69 & $\uparrow$ Granzyme B & $62,66,67$ \\
\hline Dengue & $\downarrow$ in blood & $\uparrow$ CD38 in blood & $\uparrow$ Granzyme B & 66 \\
\hline Hepatitis B virus & Marginal $\downarrow$ in blood & $\uparrow$ CD38 and CD57 in blood & $\begin{array}{l}\uparrow \text { Granzyme B and perforin; } \uparrow \\
\text { IFN } \gamma \text { (after Escherichia coli and } \\
\text { anti-CD28 stimulation) }\end{array}$ & 53,68 \\
\hline Hepatitis C virus & $\downarrow$ in blood; $\downarrow$ in liver & $\begin{array}{l}\downarrow \text { CCR5; } \uparrow \text { CD 38, PD-1, HLA-DR, } \\
\text { TIM3, CTLA4 and CD69 in blood }\end{array}$ & $\uparrow$ Granzyme B & $51,52,54,56,58$ \\
\hline HIV & $\begin{array}{l}\downarrow \text { in blood and } \\
\text { lymph nodes }\end{array}$ & $\begin{array}{l}\uparrow \text { PD-1, HLA-DR, TIM3, CD38, } \\
\text { CD57, IL-7R, CCR6, T-bet in blood }\end{array}$ & $\downarrow$ Granzyme B, IFN $\gamma$ and TNF & $55,57,61,64,65$ \\
\hline HTLV-1 & $\downarrow$ in blood & $\begin{array}{l}\uparrow \mathrm{CD} 38 \text { and HLA-DR and } \downarrow \text { PLZF } \\
\text { in blood }\end{array}$ & $\downarrow$ IFN $\gamma$ (after E. coli stimulation) & 63 \\
\hline
\end{tabular}

CCR, CC-chemokine receptor; CTLA4, cytotoxic T lymphocyte antigen 4; GM-CSF, granulocyte-macrophage colony-stimulating factor; HTLV-1, human T cell lymphotropic virus type 1; IFN $\gamma$, interferon- $\gamma$; MAIT, mucosal-associated invariant T; ND, not determined; PD-1, programmed cell death 1; TIM3, T cell immunoglobulin and mucin domain-containing 3; TNF, tumour necrosis factor.

of $\mathrm{CD} 4^{+}$MAIT cells renders their specific detection challenging, due to potential contamination by conventional $\mathrm{T}$ cells during flow cytometry analysis. Several mechanisms could explain the decreased frequency of blood MAIT cells observed in most, if not all, pathologies.

Presence of MAIT cells in inflamed tissues. Compared with tissues from healthy individuals or with unaffected tissues or blood from the same patients, the frequency of MAIT cells increases in the target tissues of patients with various immune-mediated diseases. TABLE 3 and FIG. 2 illustrate the diversity of MAIT cell localization ${ }^{16,18,73,77-79,82,86,89,96-100}$. Mouse models allow the analysis of MAIT cells in tissues that are hard to access in humans. In non-obese diabetic (NOD) mice, the mouse model of type 1 diabetes (T1D), MAIT cell frequency continuously increases in the pancreas until disease onset. Experiments involving transfer of MAIT cells into NOD recipient mice at different stages of disease showed an increase in the recruitment of MAIT cells to the pancreas of diabetic as compared with prediabetic mice ${ }^{70}$.

It should be noted that MAIT cell accumulation in affected tissues has not been found in all immunemediated diseases; some diseases may instead show a redistribution of MAIT cells. For example, in the liver of patients with cirrhosis, immunohistochemical analysis shows preferential localization of MAIT cells in the inflammatory infiltrate around the portal tract and in the fibrotic septae ${ }^{69,87}$, and in patients with Crohn's disease (CD), MAIT cells distribute specifically towards the injured part of ileum ${ }^{18}$. Fate-tracking studies should help to clarify whether and how MAIT cell recruitment to inflamed tissues contributes to their local expansion, promoting their pathogenic functions.

Several studies have suggested a key role for adhesion molecules, integrins and chemokines in the migration of MAIT cells to inflamed tissues. For example, blood MAIT cells from patients with MS express higher levels of the pro-migratory molecules P-selectin glycoprotein ligand 1 and $\alpha \mathrm{L}$ integrin (also known as CD11a) than do cells from healthy individuals ${ }^{71}$. Moreover, IL-18, which is elevated in the serum from patients with $\mathrm{MS}^{101}$, significantly upregulates the expression of $\alpha 4 \beta 1$ integrin (also known as VLA4) by CD8 ${ }^{+}$MAIT cells, compared with conventional memory $\mathrm{CD}^{+} \mathrm{T}^{+}$cells ${ }^{99}$, and $\alpha 4 \beta 1$ integrin mediates $\mathrm{CD}^{+} \mathrm{T}$ cell migration across the blood-brain barrier in $\mathrm{MS}^{102}$. In rheumatoid arthritis, high levels of TNF and IL- $1 \beta$ in the synovial fluid can upregulate the expression of adhesion molecules, such as E-selectin, by human endothelial cells ${ }^{91}$. E-selectin promotes MAIT cell binding to endothelial cells via the sialyl-Lewis X (sLex) motif, which is elevated on synovial fluid MAIT cells compared with blood MAIT cells. In patients with rheumatoid arthritis, fewer circulating MAIT cells express the sLex motif than do circulating MAIT cells from healthy controls ${ }^{91}$, suggesting that sLex ${ }^{+}$MAIT cells have migrated to the synovial fluid. TNF also upregulates the expression of CC-chemokine ligand 20 (CCL20), which might attract MAIT cells expressing CCR6 in synovial fluid ${ }^{91}$. Similarly, in children with recent-onset T1D, the frequency of blood MAIT cells is positively correlated with their expression of CCR6 $\left(\mathrm{REF}^{70}{ }^{7}\right.$ ), suggesting the involvement of CCR6 in the migration of MAIT cells to inflamed tissues. CCR6 $^{+}$cells recognize CCL20 and $\beta$-defensins, which 


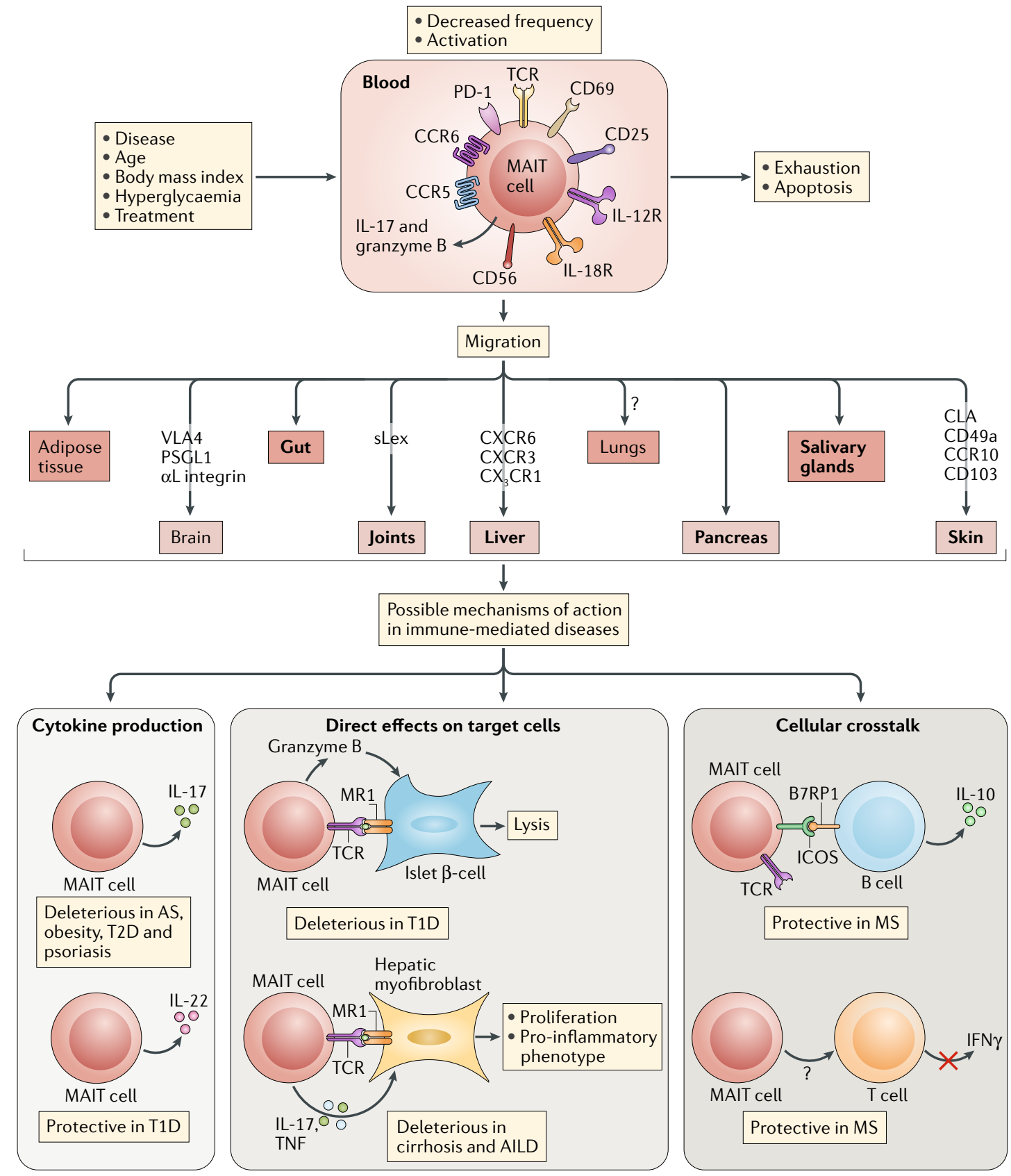

Fig. 2 | MAIT cell alterations and function in immune-mediated diseases. In most autoimmune and immune-mediated diseases, mucosal-associated invariant T (MAIT) cell numbers in the blood are decreased. This may reflect two possible mechanisms: migration of MAIT cells to inflamed tissues, or increased MAIT cell death. MAIT cells express numerous chemokine receptors (such as CCR5, CCR6 and CXCR6), integrins (such as $\alpha 4 \beta 1$ integrin, CD49a and CD103) and other adhesion molecules (such as P-selectin glycoprotein ligand 1 (PSGL1), aL integrin and sialyl-Lewis X motif (sLex)). In some disease settings, MAIT cells are chronically activated (showing expression of CD25, CD69 or CD40L) by MHC class I-related molecule (MR1) and/or cytokines (IL-12, IL-18, IL-6 and interferon- $\alpha$ (IFN $\alpha)$ ), and this can lead to a dysfunctional or exhaustion state (characterized by the expression of PD-1 and impaired IFN $\gamma$ and tumour necrosis factor (TNF) secretion) and apoptosis (marked by increased levels of FAS and intracellular active caspase 3, as well as decreased levels of BCL-2). Disease, age, body mass index, hyperglycaemia or treatment could also impact MAIT cell frequency and functions. MAIT cells have been found to have both protective and deleterious roles in various immune-mediated diseases, through multiple mechanisms involving cytokine production, direct cell contact and cellular crosstalk. MAIT cells may act directly on target cells - for example, granzyme B-mediated lysis of islet $\beta$-cells in type 1 diabetes (T1D) and MR1-dependent or cytokine-dependent activation of profibrogenic functions of liver myofibroblasts in cirrhosis and autoimmune liver disease (AILD). MAIT cells may also act through immunoregulatory pathways involving more complex cellular crosstalk such as interactions with $B$ and T cells and with myeloid cells. Bold text is used in the middle part of the figure for tissues to which MAIT cells have been shown to migrate or for which migration is strongly supported. AS, ankylosing spondylitis; B7RP1, B7-related protein 1; CLA, cutaneous lymphocyte-associated antigen; ICOS, inducible T cell co-stimulator; IL-12R, IL-12 receptor; MS, multiple sclerosis; PD-1, programmed cell death 1; T2D, type 2 diabetes; TCR, T cell receptor. 
Table 3 | MAIT cells in immune-mediated diseases

\begin{tabular}{|c|c|c|c|c|c|c|c|}
\hline \multirow[t]{2}{*}{ Disease } & \multicolumn{2}{|c|}{$\begin{array}{l}\text { MAIT cell } \\
\text { frequency }\end{array}$} & \multicolumn{2}{|c|}{ MAIT cell phenotype } & \multirow[t]{2}{*}{$\begin{array}{l}\text { MAIT cell effect } \\
\text { on disease }\end{array}$} & \multirow[t]{2}{*}{ Possible mechanisms of action } & \multirow[t]{2}{*}{ Refs } \\
\hline & Blood & Tissues & Blood & Tissues & & & \\
\hline \multirow[t]{2}{*}{$\begin{array}{l}\text { Type } 1 \text { diabetes, non-obese } \\
\text { diabetic mice }\end{array}$} & \multirow[t]{2}{*}{$\downarrow$} & \multirow[t]{2}{*}{$\uparrow \downarrow^{\mathrm{a} \leftrightarrow} \leftrightarrow^{\mathrm{a}}$} & \multirow{2}{*}{$\begin{array}{l}\text { Activated, } \\
\text { exhausted, } \\
\text { apoptotic }\end{array}$} & \multirow[t]{2}{*}{$\begin{array}{l}\text { Activated, } \\
\text { exhausted? }\end{array}$} & Protective & $\begin{array}{l}\text { Gut mucosa integrity maintained via } \\
\text { IL-17 and IL-22 production by MAIT cells }\end{array}$ & \multirow[t]{2}{*}{$70,124,131$} \\
\hline & & & & & Deleterious & $\begin{array}{l}\text { - Islet } \beta \text {-cell cytotoxic death via } \\
\text { granzyme B } \\
\text { - Granzyme B synthesis by MAIT cells in } \\
\text { pancreas of non-obese diabetic mice }\end{array}$ & \\
\hline Type 2 diabetes & $\downarrow$ & $\uparrow^{\mathrm{b}} \downarrow \leftrightarrow^{\mathrm{a}}$ & $\begin{array}{l}\text { Activated, } \\
\text { exhausted }\end{array}$ & ND & Deleterious? & $\begin{array}{l}\text { IL-17 and granzyme B production by } \\
\text { MAIT cells in blood and adipose tissue }\end{array}$ & 16,73 \\
\hline Obesity & $\downarrow^{c}$ & $\uparrow^{b} \downarrow \leftrightarrow^{a}$ & $\begin{array}{l}\text { Activated, } \\
\text { exhausted }\end{array}$ & $\begin{array}{l}\text { Activated, } \\
\text { exhausted, } \\
\text { apoptotic }\end{array}$ & Deleterious? & $\begin{array}{l}\text { - IL-17 production by MAIT cells in } \\
\text { blood and adipose tissue, insulin } \\
\text { resistance } \\
\text { - Granzyme B secretion in adipose } \\
\text { tissue }\end{array}$ & 16,73 \\
\hline Cardiovascular diseases & $\downarrow^{c}$ & ND & Apoptotic & ND & Deleterious? & Pro-inflammatory effects of MAIT cells & 94 \\
\hline $\begin{array}{l}\text { Liver cirrhosis, autoimmune } \\
\text { liver disease, carbon } \\
\text { tetrachloride-exposed } \\
\text { mice, mice undergoing bile } \\
\text { duct ligation }\end{array}$ & $\downarrow^{c}$ & $\uparrow^{b} \downarrow^{a}$ & $\begin{array}{l}\text { Activated, } \\
\text { exhausted, } \\
\text { apoptotic }\end{array}$ & $\begin{array}{l}\text { Activated, } \\
\text { exhausted? }\end{array}$ & Deleterious & $\begin{array}{l}\text { - M1 macrophage polarization by } \\
\text { MAIT cells } \\
\text { - MAIT cell interaction with } \\
\text { myofibroblasts, profibrogenic and } \\
\text { pro-inflammatory effects } \\
\text { - Increased circulating and hepatic } \\
\text { IL-17+ MAIT cells }\end{array}$ & $69,85,87$ \\
\hline $\begin{array}{l}\text { Alcohol-related liver } \\
\text { disease }\end{array}$ & $\downarrow$ & $\leftrightarrow^{\mathrm{a}}$ & $\begin{array}{l}\text { Activated, } \\
\text { exhausted }\end{array}$ & ND & Protective & $\begin{array}{l}\text { Defective antibacterial functions of } \\
\text { circulating MAIT cells }\end{array}$ & 83 \\
\hline $\begin{array}{l}\text { Type } 1 \text { autoimmune } \\
\text { hepatitis }\end{array}$ & $\downarrow$ & $\uparrow^{a}$ & $\begin{array}{l}\text { Activated } \\
\text { exhausted }\end{array}$ & ND & Deleterious? & $\begin{array}{l}\text { Increased granzyme } B^{+} \text {MAIT cell } \\
\text { frequency in blood correlates with } \\
\text { fibrosis score } \\
\text { at diagnosis }\end{array}$ & 82 \\
\hline deficient diet & $\downarrow$ & $\uparrow^{d} \downarrow^{a}$ & $\begin{array}{l}\text { Activated } \\
\text { apoptotic }\end{array}$ & Apoptotic & Deleterious? & IL-17 production by MAIT cells in blood & $18,79,8$ \\
\hline $\begin{array}{l}\text { Crohn's disease, } 2,4,6- \\
\text { trinitrobenzene sulfonic } \\
\text { acid-induced colitis mouse } \\
\text { model }\end{array}$ & $\downarrow$ & $\uparrow^{\mathrm{a}} \downarrow^{\mathrm{a}}$ & $\begin{array}{l}\text { Activated, } \\
\text { exhausted, } \\
\text { apoptotic }\end{array}$ & ND & Protective & IL-17 production by MAIT cells in blood & $18,81,125$ \\
\hline Coeliac disease & $\downarrow$ & $\downarrow^{\mathrm{a} \leftrightarrow} \mathrm{a}$ & ND & ND & ND & ND & 74 \\
\hline $\begin{array}{l}\text { X-linked lymphoprolifera- } \\
\text { tive syndrome type } 2\end{array}$ & $\downarrow$ & ND & Apoptotic & ND & ND & ND & 76 \\
\hline Sjögren syndrome & $\downarrow$ & $\uparrow^{a}$ & $\begin{array}{l}\text { Activated, } \\
\text { exhausted }\end{array}$ & Activated & Deleterious? & $\begin{array}{l}\text { IL-17 production by MAIT cells in } \\
\text { salivary glands }\end{array}$ & 78,86 \\
\hline Ankylosing spondylitis & $\downarrow$ & $\uparrow^{b}$ & $\begin{array}{l}\text { Activated } \\
\text { exhausted }\end{array}$ & $\begin{array}{l}\text { Activated, } \\
\text { exhausted }\end{array}$ & Deleterious? & $\begin{array}{l}\text { - IL-17 and granzyme B production by } \\
\text { MAIT cells in synovial fluid } \\
\text { - IL-17 and IL- } 22 \text { production by } \\
\text { circulating MAIT cells }\end{array}$ & $77,80,84$ \\
\hline $\begin{array}{l}\text { Rheumatoid arthritis, } \\
\text { collagen-induced arthritis } \\
\text { mouse model }\end{array}$ & $\downarrow^{c}$ & $\uparrow^{\mathrm{b}}$ & Activated & Activated & Deleterious & $\begin{array}{l}\text { - Reduced disease severity in } \mathrm{Mr}^{-/-} \\
\text {mice, enhanced disease severity in } \\
\text { Va19 transgenic mice } \\
\text { - Reduced IL-17 production in liver of } \\
\text { Mr1 } 1^{-1-} \text { mice }\end{array}$ & $89,91,117$ \\
\hline $\begin{array}{l}\text { Systemic lupus } \\
\text { erythematosus }\end{array}$ & $\downarrow^{c}$ & ND & $\begin{array}{l}\text { Activated } \\
\text { exhausted, } \\
\text { apoptotic }\end{array}$ & ND & ND & $\begin{array}{l}\text { Correlation between disease activity } \\
\text { and frequency of CD } 69^{+} \text {circulating } \\
\text { MAIT cells }\end{array}$ & 88,89 \\
\hline
\end{tabular}


Table 3 (cont.) | MAIT cells in immune-mediated diseases

\begin{tabular}{|c|c|c|c|c|c|c|c|}
\hline \multirow[t]{2}{*}{ Disease } & \multicolumn{2}{|c|}{$\begin{array}{l}\text { MAIT cell } \\
\text { frequency }\end{array}$} & \multicolumn{2}{|c|}{ MAIT cell phenotype } & \multirow[t]{2}{*}{$\begin{array}{l}\text { MAIT cell effect } \\
\text { on disease }\end{array}$} & \multirow[t]{2}{*}{ Possible mechanisms of action } & \multirow[t]{2}{*}{ Refs } \\
\hline & Blood & Tissues & Blood & Tissues & & & \\
\hline $\begin{array}{l}\text { Antineutrophil cytoplasmic } \\
\text { antibody-associated } \\
\text { vasculitis }\end{array}$ & $\downarrow$ & ND & Activated & ND & ND & ND & 72,75 \\
\hline \multirow[t]{2}{*}{$\begin{array}{l}\text { Multiple sclerosis, } \\
\text { experimental autoimmune } \\
\text { encephalomyelitis mouse } \\
\text { model }\end{array}$} & \multirow[t]{2}{*}{$\uparrow \downarrow^{c}$} & \multirow[t]{2}{*}{$\uparrow^{\mathrm{a}} \downarrow^{\mathrm{b}}$} & \multirow[t]{2}{*}{ Activated } & \multirow[t]{2}{*}{ Activated } & $\begin{array}{l}\text { Protective, } \\
\text { immunoregulatory }\end{array}$ & $\begin{array}{l}\text { - Increased IL-10 production by B cells } \\
\text { and decreased pro-inflammatory } \\
\text { molecules, due to Va19 cell } \\
\text { interaction with B cells via ICOS } \\
\text { IFN } \gamma \text { production by T cells suppressed } \\
\text { in a cell-contact-dependent manner } \\
\text { via MAIT cell interaction with T cells }\end{array}$ & \multirow[t]{2}{*}{$\begin{array}{r}71,95, \\
96,99,111, \\
118,126,158\end{array}$} \\
\hline & & & & & Deleterious? & $\begin{array}{l}\text { - Switch of MAIT cells toward } T_{H} \text { 17-type } \\
\text { profile } \\
\text { - Increased MR1- and cytokine- } \\
\text { dependent activation of MAIT cells in } \\
\text { the CNS }\end{array}$ & \\
\hline Asthma & $\downarrow^{c}$ & $\downarrow^{\mathrm{a}}$ & Activated $^{c}$ & ND & Protective? & $\begin{array}{l}\text { - Lower circulating MAIT cell frequency } \\
\text { in 1-year-old children who develop } \\
\text { asthma at age } 7 \\
\text { Interaction between MAIT cells and } \\
\text { CD4 } 4^{+} \text {T cells that induce IFN } \gamma\end{array}$ & $90,92,129,15$ \\
\hline Psoriasis & ND & $\leftrightarrow^{\mathrm{a}}$ & ND & Activated & Deleterious? & $\begin{array}{l}\text { IL-17 and IL-22 production by MAIT cells } \\
\text { in skin }\end{array}$ & 98 \\
\hline Dermatitis herpetiformis & ND & $\uparrow^{a}$ & ND & ND & ND & ND & 97 \\
\hline
\end{tabular}

Exhausted? denotes a cell status based only on phenotype and not confirmed by functional analysis. Exhausted denotes cells with impaired cytokine production and function. Deleterious? denotes a deleterious effect is suggested or hypothetical and not yet demonstrated. Protective? denotes a protective effect is suggested or hypothetical and not yet demonstrated. $\uparrow$, increased frequency; $\downarrow$, decreased frequency; $\uparrow \downarrow$, both increased and decreased frequency reported; $\leftrightarrow$, no change; CNS, central nervous system; ICOS, inducible T cell co-stimulator; IFN $\gamma$, interferon- $\gamma$; MAIT, mucosal-associated invariant T; MR1, MHC class I-related molecule; ND, not determined; $\mathrm{T}_{\mathrm{H}} 17$, T helper $17 .{ }^{\mathrm{a}} \mathrm{C}$ Compared with tissues from healthy individuals or with unaffected tissues. ${ }^{\mathrm{b}} \mathrm{Compared}$ with blood.

${ }^{\mathrm{C}}$ Correlation with disease severity. ${ }^{\mathrm{d}} \mathrm{C}$ omparison between active and inactive forms of the disease.

are chemoattractants that are increased in the pancreas and gut of diabetic patients and mouse models ${ }^{103-105}$. In addition to CCR6, other skin-homing receptors, such as CCR10, CD49a, CD103 and cutaneous lymphocyteassociated antigen, are expressed by some blood MAIT cells ${ }^{19,97,98}$ and could participate in their migration to dermatitis herpetiformis lesions, in which MAIT cells are abundant ${ }^{97}$. Increased expression of the chemokine receptors $\mathrm{CXCR} 3$ and $\mathrm{CX}_{3} \mathrm{CR} 1$ on hepatic MAIT cells in non-infectious chronic liver diseases might reflect their activation rather than their recruitment, as MAIT cells are already abundant in the liver at the steady state ${ }^{15}$. Of note, even though MAIT cells express various chemokine receptors (TABLE 1), until now, no specific subset of MAIT cells has been identified as preferentially trafficking to distinct tissues.

Blood MAIT cells are activated and exhausted. The decreased frequency of blood MAIT cells in immunemediated diseases could also result from their death by apoptosis subsequent to sustained activation. Accordingly, in many autoimmune and inflammatory diseases, circulating MAIT cells express higher levels of activation and/or exhaustion markers, such as CD38, CD25, CD69 and PD-1 (REFS ${ }^{16,18,69,70,73,83,85,87,89,93}$ ). Furthermore, in some diseases MAIT cell activation correlates with disease activity score (TABLE 3). As has been observed in infectious diseases, MAIT cells could be activated via MR1-dependent or MR1-independent pathways. In systemic lupus erythematosus (SLE), the increased activation of MAIT cells has partly been explained by the increased ability of monocytes to activate MAIT cells in a TCR-dependent manner ${ }^{88}$. The activation of MAIT cells by MR1 in autoimmune and immune-mediated diseases is also suggested by the observation of increased MR1 expression in inflamed tissues $^{71}$. In the context of T1D, in vitro exposure of a human pancreatic $\beta$-cell line to pro-inflammatory cytokines increases both $M R 1$ transcript levels and MR1 surface expression ${ }^{70}$. Interestingly, gut homeostasis is altered in many autoimmune and immune-mediated diseases (BOX 2), which could lead to increased levels of bacteria-derived ligands for MR1. The observations of thymic selection of MAIT cells in germ-free mice ${ }^{106}$ and TCR-dependent activation of myofibroblasts by MAIT cells in the absence of exogenous ligands ${ }^{69}$ support the existence of endogenous ligands (BOX 1). Moreover, correlations between circulating MAIT cell frequency, $\mathrm{CD} 9^{+}$MAIT cell frequency and cytokine (IL-18, IL-6 and IFNa) plasma levels in patients with $\mathrm{SLE}^{88}, \mathrm{MS}^{99}$ and ulcerative colitis (UC) ${ }^{79}$ suggest that MAIT cells can also be activated by cytokines in these diseases. The exact mechanism of MAIT cell activation is not yet well defined. As in infectious diseases, the combined triggers for MAIT cell activation of inflammatory cytokines and TCR-mediated signals might lead to 


\section{Box 2 | MAIT cells and gut alteration in immune-mediated diseases}

Studying mucosal-associated invariant T (MAIT) cells in autoimmune, inflammatory and metabolic diseases can shed new light on the pathophysiology of these cells. Despite their different features, many of the pathologies listed are associated with alterations in gut homeostasis ${ }^{149-151}$, including microbiota composition, intestinal permeability and gut immunity. Given the key characteristics of MAIT cells (activation by bacterial ligands, homing capacity and gut localization), they might represent sensors and/or enactors of such gut modifications. But what is the first step during autoimmune, inflammatory and metabolic diseases? Are MAIT cells first impaired by the inflammation occurring in inflamed tissues, or is microbiota dysbiosis the initial impact modifying MAIT cell function? Inflammation outside of the gut can activate and alter the function of the MAIT cells that subsequently migrate to the gut mucosa, where they are no longer able to maintain gut homeostasis, as suggested by the decreased production of IL-17 and IL-22 by intestinal MAIT cells in the non-obese diabetic (NOD) mouse model of type 1 diabetes ${ }^{24,70}$. Impaired MAIT cells might also lose their ability to provide efficient antibacterial function. Together, these MAIT cell alterations could promote gut mucosa and microbiota alterations.

In a second hypothesis, initial modifications of gut homeostasis, such as increased bacterial translocation and modification of the intestinal microbiota, could alter the equilibrium between different bacteria and the level of activating and/or inhibiting ligands, thereby impacting MAIT cell functions. Identifying the kinetics and nature of MAIT cell interactions with the gut mucosa and microbiota represents a critical step for exploring MAIT cell-based treatments for autoimmune, inflammatory, metabolic and immune-mediated diseases.
It would be interesting to analyse whether chronic inflammation, often associated with autoimmune diseases, dampens XIAP expression by MAIT cells.

\section{Increased apoptosis of MAIT cells in target tissues.} As we mentioned above, MAIT cells have the propensity to migrate to inflamed tissues, and in many autoimmune and immune-mediated diseases MAIT cell frequency is increased in target tissues. However, in some tissues, such as the liver, colon and adipose tissue, where MAIT cells are abundant in the steady state, their frequency tends to decrease upon inflammation. These results suggest that increased apoptosis of MAIT cells could override potential MAIT cell recruitment in these inflamed tissues. For example, MAIT cells are less frequent in inflamed intestinal mucosa of patients with UC and $\mathrm{CD}$ and of children with coeliac disease, compared with healthy tissue $\mathrm{e}^{74,81}$. Decreased frequency of MAIT cells is also observed in adipose tissue from obese adults compared with the adipose tissue from lean adults, and in co-cultures of MAIT cells and adipose tissue from obese individuals BCL-2 expression is decreased compared with adipose tissue from lean individuals ${ }^{16,73}$. Similarly, MAIT cells are less frequent in the livers of patients with cirrhosis and autoimmune liver disease (AILD) and have an activated/exhausted phenotype (CTLA $4^{+}$and PD- $1^{+}$), as compared with control livers ${ }^{69,87}$. Intrahepatic MAIT cell frequency is negatively correlated with the PD-1 expression of the cell. Increased MAIT cell proliferation is observed in the blood of patients with $\mathrm{CD}^{18}$ and with liver cirrhosis ${ }^{69,83}$, as well as in vitro in the presence of inflamed adipose tissue from obese patients ${ }^{16}$; however, this proliferation is not sufficient to compensate for the loss of MAIT cells. cell exhaustion has been associated with dysfunction of the $\mathrm{Ca}^{2+}$-calcineurin-NFAT1 signalling pathway downstream of TCR stimulation ${ }^{89}$. Although MAIT cells from most immune-mediated diseases show defective activation and/or IFN $\gamma$ and TNF production in vitro, several studies have described an increased frequency of MAIT cells producing IL-17 in the same pathologies ${ }^{16,18,70,73,77}$. These observations suggest there is heterogeneity among MAIT cells, a hypothesis that is worthy of more detailed analysis.

Increased apoptosis of blood MAIT cells. MAIT cells in many immune-mediated diseases show increased apoptosis, possibly as a result of chronic activation. In children with recent-onset $\mathrm{T} 1 \mathrm{D}$, fewer circulating MAIT cells express the anti-apoptotic factor BCL-2, and this is positively correlated to the overall frequency of MAIT cells ${ }^{70}$. A similar correlation is also observed in patients with liver cirrhosis ${ }^{69}$. In patients with UC, CD and SLE, more circulating MAIT cells express activated caspases (which mediate apoptotic cell death) than in control individuals ${ }^{81,88}$. X-linked lymphoproliferative syndrome type 2 (XLP2) is a rare human genetic immunodeficiency with some clinical signs similar to CD. XLP2 results from mutations in the gene encoding $\mathrm{X}$-linked inhibitor of apoptosis (XIAP) and leads to a proapoptotic phenotype in invariant natural killer T (iNKT) cells and MAIT cells, which could explain the decreased frequency of such cells in the blood of these patients ${ }^{76}$.
Other factors impacting MAIT cell frequency. The marked heterogeneity among patients with regard to factors - such as age ${ }^{107,108}$, body mass index ${ }^{16,73}$, physical activity ${ }^{109}$ and ongoing treatment ${ }^{69,90,110}$ — that could impact MAIT cell frequency and function might explain the conflicting results in human studies ${ }^{71,111}$. For example, decreased blood MAIT cell frequency is observed in adults but not in children with coeliac disease $\mathrm{e}^{74}$, and in obesity MAIT cell frequency is increased in children but decreased in adults ${ }^{16,73}$. Whether the strong decrease of MAIT cell frequency reported in patients with severe asthma results from the pathophysiology or from the inhaled corticoid treatment is unclear ${ }^{90}$. Indeed, the lower MAIT cell frequencies in the blood, sputum and endobronchial biopsies of asthmatic patients are positively associated with disease severity and negatively associated with inhaled corticosteroids. No change in MAIT cell frequency is observed in the broncho-alveolar lavage fluid from asthmatic patients, which could reflect the weak diffusion of the inhaled corticosteroids in more distal airways and the alveolar compartment ${ }^{90}$. However, in another study, after exclusion of patients on corticoid treatment, the re-evaluated circulating MAIT cell frequency was still decreased in patients with inflammatory bowel diseases ${ }^{112}$. Moreover, decreased MAIT cell frequency has been observed in other autoimmune or immune-mediated 
diseases in patients without immune-modulating treatments ${ }^{16,69,70,73,74,83,93}$.

An impact of hyperglycaemia on MAIT cell frequency has been proposed. In cardiovascular disease, circulating MAIT cell frequency negatively correlated to glycated haemoglobin $\left(\mathrm{HbA}_{1 \mathrm{c}}\right)$ levels ${ }^{94}$, and in obese patients, decreased circulating MAIT cell frequency was greater in adults with uncontrolled $\mathrm{HbA}_{1 c}$ levels ${ }^{73}$. Moreover, exposure of MAIT cells to glucose increases their apoptosis in a dose-dependent manner ${ }^{94}$. While no correlation was observed between $\mathrm{HbA}_{1 \mathrm{c}}$ level and blood MAIT cell frequency in children with T1D, granzyme $\mathrm{B}^{+}$MAIT cell frequency was inversely correlated with $\mathrm{HbA}_{1 \mathrm{c}}$ levels at the onset of disease, but not in children with established disease ${ }^{70}$. The potential role of granzyme $\mathrm{B}^{+}$MAIT cells in T1D is further discussed below. Together, these observations suggest that decreased MAIT cell frequency in various diseases might have multifactorial origins.

\section{Pathogenic roles for MAIT cells}

Pathogenic role of MAIT cells in the liver. During chronic liver injury, signals originating from immune cells, as well as bacterial by-products, play central roles in the progression of liver fibrosis by activating the fibrogenic functions of hepatic myofibroblasts and their inflammatory properties. In the liver of patients with cirrhosis and AILD, MAIT cells accumulate in the fibrotic septa ${ }^{69,87}$, making contact with hepatic myofibroblasts. Their profibrogenic functions were demonstrated in mouse models, in which deficiency of $M r 1$ led to resistance to fibrosis induced by chronic carbon tetrachloride administration or bile-duct ligation, whereas expression of a Va19TCR transgene, leading to an excess of MAIT cells, resulted in mice that were more prone to fibrosis ${ }^{69}$. In vitro, MAIT cells enhanced the fibrogenic functions of hepatic myofibroblasts, characterized by increased proliferation and collagen secretion, and exacerbated their pro-inflammatory properties ${ }^{69,87}$. Interestingly, hepatic myofibroblasts express MR1 at the cell surface and are activated by MAIT cells via an MR1-dependent pathway. By contrast, the myofibroblast pro-inflammatory properties can be induced in a contact-independent manner by TNF or IL-17A released by MAIT cells ${ }^{69,87}$. In addition to directly interacting with fibrogenic cells, MAIT cells may also favour fibrosis progression by fostering a local inflammatory reaction, in that they promote polarization of macrophages towards a pro-inflammatory phenotype $^{69}$.

Pathogenic role of IL-17-producing MAIT cells. All human and most mouse MAIT cells express ROR $\gamma \mathrm{t}$, a master transcription factor controlling IL-17 production $^{22,113-115}$. IL-17 has pathogenic roles in many autoimmune, metabolic and liver diseases ${ }^{116}$, suggesting that MAIT cells could be deleterious via IL-17 production. In the collagen-induced arthritis murine model, MAIT cells are pro-inflammatory ${ }^{117}$, in that the severity of the disease is reduced in $\mathrm{MrI}^{-/-}$mice and enhanced after $\mathrm{T}$ cell transfer from Va19TCRtransgenic mice. Accordingly, total splenocytes from $\mathrm{MrI}^{-/-}$mice produce lower levels of IL-17 after anti-CD3 and anti-CD28 stimulation or IL-23 treatment. Human studies highlight a switch towards a $\mathrm{T}_{\mathrm{H}} 17$-type profile of blood MAIT cells, with an increase in secretion of IL-17 in patients with $\mathrm{CD}^{18}, \mathrm{UC}^{18,79}$, ankylosing spondylitis (AS $)^{77}$, obesity ${ }^{16,73}$, type 2 diabetes (T2D) ${ }^{16}$ and cirrhosis $^{69}$, and of IL-22 in patients with $\mathrm{UC}^{18}$ and $\mathrm{AS}^{84}$. Analysis of MAIT cells in patients with MS has further shown increased expression of ROR $\gamma t$, CCR6 and IL-7R compared with healthy controls ${ }^{118}$. Similarly, IL-17 production is increased in MAIT cells from the salivary glands of patients with Sjögren syndrome (SS) compared with controls ${ }^{78,86}$, as well as after stimulation with IL-23 in vitro ${ }^{78}$. In AS, the altered cytokine profile of blood MAIT cells is also observed in the synovial fluid in favour of IL-17 production 7,84 , and IL-7 priming of MAIT cells increases IL-17 production in patients compared with healthy controls ${ }^{77}$. Of note, IL-7 levels are elevated in the joints and gut of AS patients ${ }^{119,120}$, and there is a positive correlation between IL-7 and IL-17 levels in these patients ${ }^{121}$. Interestingly, circulating MAIT cells from patients with AS have higher IL-7R expression levels than in controls ${ }^{77}$. There is a report of IL-17 and IL-22 production by a MAIT cell clone derived from psoriatic skin lesions ${ }^{98}$. Adipose tissue from obese individuals had an elevated frequency of MAIT cells that produce IL-17 compared with controls ${ }^{16,73}$, which might induce insulin resistance in adipocytes $^{122,123}$. Interestingly, the pathogenic role for IL-17-producing MAIT cells is suggested in asthmatic children, in whom there is a correlation between cell frequency and disease severity (defined as the number of exacerbations) $)^{92}$. Most of these analyses in humans have shown correlations between MAIT cells, IL-17 production and disease status, but further studies are warranted to demonstrate causality.

Pathogenic role of cytotoxic MAIT cells. MAIT cells could have a pathogenic role in autoimmune and immune-mediated diseases via their cytotoxic properties. T1D is the most obvious example of this activity ${ }^{70}$. Analysis of NOD mice has revealed an increasing level of granzyme B expression in pancreatic islets from the prediabetic stage to diabetes onset. In humans, more circulating MAIT cells produce granzyme B in children with recent onset T1D than do control MAIT cells. Interestingly, granzyme $\mathrm{B}^{+}$MAIT cell frequency correlated negatively with the frequency of MAIT cells and with the age of the child at diagnosis, in agreement with the current view that T1D is more aggressive in the youngest children. These data in NOD mice and T1D patients suggest that MAIT cells could kill pancreatic $\beta$-cells, even though to date MAIT cells have not been detected in diseased islets ${ }^{124}$. As we mentioned earlier, MR1 expression is upregulated on the human $\beta$-cell line EndoC- $\beta \mathrm{H} 1$ in the presence of pro-inflammatory cytokines, and in co-cultures MAIT cells from healthy controls can kill EndoC- $\beta \mathrm{H} 1$ cells in an MR1-dependent manner $^{70}$.

A similar pathogenic local effect of granzyme $\mathrm{B}^{+}$ MAIT cells is also suggested in patients with $\mathrm{AS}^{77}$ and in obesity $^{16}$. Of note, in NOD mice the presence of granzyme $\mathrm{B}^{+}$MAIT cells in the intestinal mucosa increases with diabetes development, indicative of their potential 
pathogenic role in this tissue before and at T1D onset (L. Beaudoin and A.L., unpublished observations). Together, these studies show that MAIT cells can mediate various pathogenic mechanisms.

\section{A protective role for MAIT cells}

Immunoregulatory role of MAIT cells. In contrast to their potentially pathogenic activities, MAIT cells also have immunoregulatory activities that may be protective in disease. MAIT cells have a protective role in the 2,4,6-trinitrobenzene sulfonic acid (TNBS)-induced colitis mouse model ${ }^{125,126}$. MAIT cells are decreased in the colonic mucosa after TNBS treatment, and transfer of Ja33TCR ${ }^{+}$MAIT cells reduces the severity of the disease, weight loss, intestinal bleeding and colonic inflammation. In experimental autoimmune encephalomyelitis (EAE) ${ }^{126}$, the mouse model of MS, transgenic expression of the invariant Va19TCR in T cells protects mice from EAE induction, and adoptive transfer of

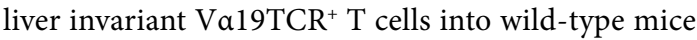
with EAE reduces the disease severity. Conversely, EAE in $\mathrm{Mr}^{1^{-1-}}$ mice is exacerbated ${ }^{126}$. The suppression of EAE by invariant $\mathrm{Va19} \mathrm{TCR}^{+} \mathrm{T}$ cells is associated with reduced expression of pro-inflammatory molecules and increased production of IL-10 by B cells, through an inducible $\mathrm{T}$ cell co-stimulator-dependent interaction with invariant Va19TCR ${ }^{+} \mathrm{T}$ cells ${ }^{126}$. IL-10 can inhibit excessive gut inflammation ${ }^{127}$ and is implicated in IgA production $^{128}$. A regulatory role of IL-10-secreting MAIT cells is also suggested by their presence in the adipose tissue of lean individuals but their reduced frequency in obese individuals ${ }^{73}$. In vitro experiments also support the immunoregulatory function of MAIT cells from both patients with MS and healthy adults ${ }^{95}$, as they suppress IFN $\gamma$ production by conventional T cells in a cell contact-dependent manner.

In a longitudinal study, the circulating MAIT cell frequency was shown to be lower in 1-year-old children who later develop asthma than in 1-year-olds who do not. A higher MAIT cell frequency is correlated with stronger IFN $\gamma$ secretion by $\mathrm{CD} 4^{+} \mathrm{T}$ cells, suggesting a protective role of MAIT cells associated with a potent $\mathrm{T}_{\mathrm{H}}$ 1-type immune response $\mathrm{e}^{129}$. It would be interesting to determine whether there is a link between these observations in children and the hygiene hypothesis, implying that activation of the immune system at a young age can promote immunoregulatory mechanisms ${ }^{130}$ and that MAIT cells could represent an ideal immune cell type to maintain regulatory function in the whole body.

Prevention of T1D by MAIT cells. Concerning T1D, an initial study suggested a protective role for MAIT cells, as diabetes is delayed in Va19TCR-transgenic NOD mice ${ }^{131}$. More recently, analysis of $\mathrm{Mr}^{-/-} \mathrm{NOD}$ mice confirmed the protective role of MAIT cells, as these mice develop accelerated diabetes, despite the potential pathogenic role of MAIT cells in the pancreas ${ }^{70}$. Indeed, this study suggests that MAIT cells could have a protective role in the gut mucosa through their production of IL-17 and IL-22, two cytokines required for the maintenance of gut barrier integrity. In $\mathrm{MrI}^{-1-} \mathrm{NOD}$ mice, exacerbation of diabetes development is associated with a loss of gut barrier integrity, allowing the translocation of bacterial compounds and subsequent dendritic cell activation in pancreatic lymph nodes ${ }^{70}$. Of note, a protective role of IL-17 has been established in several intestinal inflammation models ${ }^{116}$, and IL-22+ MAIT cells have been observed in the blood of patients with $\mathrm{UC}^{18}$ and $\mathrm{AS}^{84}$.

Protective role of MAIT cells in the liver. In patients with nonalcoholic fatty liver disease (NAFLD), MAIT cells accumulate around fatty hepatocytes. Although mouse and human studies have demonstrated the profibrogenic properties of MAIT cells, $\mathrm{Mr}^{1^{-1-}}$ mice fed a methionine-choline-deficient diet show enhanced steatosis, are more prone to liver injury and have more CD11 ${ }^{+}$M1-like inflammatory macrophages but fewer $\mathrm{CD}^{206^{+}}$M2-like macrophages ${ }^{93}$. Future studies will be needed to confirm this protective role of MAIT cells in a more relevant model of nonalcoholic steatohepatitis, and the contribution of IL-17 needs to be evaluated, as it is a major driver of NAFLD progression ${ }^{132,133}$. In addition, it remains unclear whether gut-derived bacterial components impact MAIT cell activation during NAFLD.

Patients with alcoholic liver disease, either severe alcoholic hepatitis or end-stage cirrhosis, are at high risk of developing bacterial infections, because of a leaky gut, gut dysbiosis, increased bacterial translocation and dysregulation of immune cell functions. In in vitro experiments, stool extracts from patients with alcoholic liver disease induced MAIT cell depletion and suppressed their antibacterial cytokine (IL-17, TNF and IFN $\gamma$ ) responses and the expression of PLZF and ROR $\gamma t$, which are involved in MAIT cell maturation and effector functions ${ }^{83}$. These data suggest that MAIT cell functional defects in patients with alcohol-related liver disease could contribute to this population's high susceptibility to bacterial infection, which is also described during autoimmune hepatitis ${ }^{82}$. Interestingly, prophylactic administration of antibiotics to patients with severe alcoholic cirrhosis, a treatment usually administered so as to avoid bacterial infections, partially prevents blood MAIT cell reduction and activation ${ }^{69}$.

Together, MAIT cells can have multiple functions, and their pathogenic or protective role may rely on their activation or exhaustion status, tissue localization and cytokine profile, and on the chronicity of the disease. Even though the characterization of blood MAIT cells might not be as informative as tissue analysis, blood MAIT cells do seem to reflect the status of MAIT cells in inflamed tissues.

\section{MAIT cells in human cancers}

Recent studies have investigated the role of MAIT cells in cancer, and the observations reported are similar to those made in autoimmune and inflammatory diseases (TABLES 3,4). Circulating MAIT cell frequency is decreased in patients with colorectal cancer (CRC) ${ }^{134-136}$, hepatocellular carcinoma (HCC) $)^{137}$ and lung cancer ${ }^{136}$. MAIT cells accumulate in tumour tissues from patients with colon adenocarcinomas ${ }^{138}$ and CRC, particularly in those with advanced CRC ${ }^{134-136}$, and in hepatic metastatic lesions in patients with $\mathrm{CRC}^{139}$. In contrast, in 
Table 4 | MAIT cells in cancer

\begin{tabular}{|c|c|c|c|c|c|c|c|}
\hline \multirow[t]{2}{*}{ Cancer } & \multicolumn{2}{|c|}{$\begin{array}{l}\text { MAIT cell } \\
\text { frequency }\end{array}$} & \multicolumn{2}{|c|}{ MAIT cell phenotype } & \multirow{2}{*}{$\begin{array}{l}\text { MAIT cell } \\
\text { effect on } \\
\text { disease }\end{array}$} & \multirow[t]{2}{*}{ Possible mechanisms of action } & \multirow[t]{2}{*}{ Refs } \\
\hline & Blood & Tissues & Blood & Tissues & & & \\
\hline Kidney & $\downarrow$ & $\uparrow$ & ND & ND & ND & Increased MAIT cells in tumour tissue & 160 \\
\hline Brain & $\downarrow$ & $\uparrow$ & ND & ND & ND & Increased MAIT cells in tumour tissue & 160 \\
\hline Lung & $\downarrow$ & ND & ND & ND & ND & ND & 136 \\
\hline Breast & $\leftrightarrow$ & ND & ND & ND & ND & $\begin{array}{l}\text { Increased IL-17 produced by breast duct } \\
\text { MAIT cells }\end{array}$ & 136,161 \\
\hline Colorectal & $\downarrow$ & $\uparrow$ & ND & ND & Protective? & $\begin{array}{l}\text { - Increased MAIT cells in tumour tissue } \\
\text { - Increased CD69 and PD-1 expression } \\
\text { - Decreased IFN } \gamma \text { production }\end{array}$ & $134-136,138$ \\
\hline Hepatic metastasis & ND & $\uparrow$ & ND & ND & $\begin{array}{l}\text { Protective and/ } \\
\text { or deleterious? }\end{array}$ & $\begin{array}{l}\text { - Increased MAIT cells in tumour tissue } \\
\text { - Decreased IFN } \gamma \text { production and increased } \\
\text { IL-17 production }\end{array}$ & 139 \\
\hline $\begin{array}{l}\text { Graft-versus-host disease } \\
\text { (in individuals treated for } \\
\text { cancer with bone marrow } \\
\text { transplant) }\end{array}$ & $\downarrow$ & ND & ND & ND & Protective & $\begin{array}{l}\text { Low MAIT cell frequency associated with } \\
\text { poor clinical outcome }\end{array}$ & $140-142$ \\
\hline
\end{tabular}

Exhausted denotes cells with impaired cytokine production and function. Deleterious? denotes a deleterious effect is suggested or hypothetical and not yet demonstrated. Protective? denotes a protective effect is suggested or hypothetical and not yet demonstrated. $\uparrow$, increased frequency; $\downarrow$, decreased frequency; $\leftrightarrow$, no change; IFN $\gamma$, interferon- $\gamma$; MAIT, mucosal-associated invariant T; ND, not determined; PD-1, programmed cell death 1.

patients with HCC, the frequency of MAIT cells was decreased in the liver, and in the tumour, when compared with healthy controls. As we observed in immunemediated diseases, this could reflect increased apoptosis of MAIT cells, possibly as a result of their chronic activation. Indeed, in patients with HCC, tumour-infiltrating MAIT cells had an exhausted phenotype, with high PD-1, CTLA4 and TIM3 expression, and produced less IFN $\gamma$ and IL-17 than MAIT cells from healthy donors ${ }^{137}$. Similarly, MAIT cells from colonic adenocarcinomas produced less IFN $\gamma$ than MAIT cells from healthy colons $^{138}$, suggesting that tumour-infiltrating MAIT cells might be altered due to tumour microenvironmental factors. Furthermore, tumour-infiltrating MAIT cells produced less IFN $\gamma$ than MAIT cells from healthy livers in response to recombinant IL-12 and IL-18 $\left(\right.$ REF. $\left.{ }^{139}\right)$. As was observed in other diseases, circulating MAIT cells in patients with CRC produce more IL-17 and less IFN $\gamma$ and $\mathrm{TNF}^{134}$. Of note, chemotherapy does not alter the ability of MAIT cells to produce IFN $\gamma$, nor their frequency ${ }^{139}$, in agreement with their expression of the multidrug resistance transporter ABCB1 (REF. ${ }^{11}$ ). High frequencies of tumour-infiltrating MAIT cells are associated with poor clinical outcomes for patients with HCC. In contrast, in the context of haematological malignancies, a higher frequency of MAIT cells after allogeneic haematopoietic cell transplantation is associated with less graft-versus-host disease (GVHD) ${ }^{140,141}$. Mouse studies have also shown a beneficial role of MAIT cells against GVHD and highlighted their role in maintaining gut integrity ${ }^{142}$. All these studies suggest that MAIT cells could represent attractive therapeutic targets; however, their precise role in cancer needs further investigation.

\section{Conclusion and perspectives}

MAIT cells provide efficient protection against acute bacterial and viral infections. However, in chronic pathological situations, including chronic viral infections and autoimmune, inflammatory and metabolic diseases, MAIT cells can play a pathogenic role by sustaining inflammation and cytotoxicity. This ambivalent function is reminiscent of NKT cells, which share many features with MAIT cells ${ }^{22,143,144}$, although the ligands recognized by the two innate-like $\mathrm{T}$ cell populations are quite distinct. Several endogenous ligands of NKT cells have been described ${ }^{145,146}$; however, the MAIT cell endogenous ligands remain to be identified. Although both MAIT and NKT cells are conserved in mammals, MAIT cells are much more abundant than NKT cells in humans ${ }^{144}$. Moreover, MAIT cell localization in the gut mucosa and their recognition of bacterial ligands might play a key role in sensing any modification of the microbiota composition ${ }^{147}$, either commensal or pathogenic, which might reflect the infectious, metabolic and general health status of the individual (BOX 2). Further studies should be performed to provide a better understanding of the functional plasticity of MAIT cells, the epigenetic regulation of MAIT cell function, the impact of their TCR repertoire, and their interactions with other immune and non-immune cells in physiological and pathological situations. Many of the data presented in this Review highlight MAIT cells as biomarkers in various diseases; however, new insights into their biological functions are still awaited, to inform the design of therapeutic approaches based on MAIT cell manipulation.

Published online: 15 July 2019 
1. Porcelli, S., Yockey, C. E., Brenner, M. B. \& Balk, S. P. Analysis of $\mathrm{T}$ cell antigen receptor (TCR) expression by human peripheral blood CD4-8- alpha/beta T cells demonstrates preferential use of several $\mathrm{V}$ beta genes and an invariant TCR alpha chain. J. Exp. Med. 178, $1-16$ (1993).

2. Tilloy, F. et al. An invariant T cell receptor alpha chain defines a novel TAP-independent major histocompatibility complex class lb-restricted alpha/beta $T$ cell subpopulation in mammals. J. Exp. Med. 189, 1907-1921 (1999).

3. Treiner, E. et al. Selection of evolutionarily conserved mucosal-associated invariant T cells by MR1. Nature 422, 164-169 (2003).

This study describes for the first time MAIT cell restriction to the non-polymorphic MHC class I-like protein MR1.

4. Martin, E. et al. Stepwise development of MAIT cells in mouse and human. PLOS Biol. 7, e54 (2009).

5. Gold, M. C. et al. Human mucosal associated invariant T cells detect bacterially infected cells. PLOS Biol. 8, e1000407 (2010).

6. Georgel, P., Radosavljevic, M., Macquin, C. \& Bahram, S The non-conventional MHC class I MR 1 molecule controls infection by Klebsiella pneumoniae in mice. Mol. Immunol. 48, 769-775 (2011).

7. Le Bourhis, L. et al. Antimicrobial activity of mucosalassociated invariant T cells. Nat. Immunol. 11, 701-708 (2010).

Gold et al. and Le Bourhis et al. were the first to show human MAIT cell activation by bacteriainfected cells in an MR1-dependent manner.

8. Kjer-Nielsen, L. et al. MR1 presents microbial vitamin B metabolites to MAIT cells. Nature 491 717-723 (2012)

This is the first study to describe that MR1 binds to vitamin $B$ metabolites derived from the vitamin $B_{2}$ pathway or from vitamin $B_{9}$ photodegradation.

9. Corbett, A. J. et al. T cell activation by transitory neo-antigens derived from distinct microbial pathways. Nature 509, 361-365 (2014).

This study deciphers the mechanisms by which vitamin $B_{2}$-derived activating ligands for MAIT cells are synthetized.

10. Eckle, S. B. et al. Recognition of vitamin B precursors and byproducts by mucosal associated invariant T cells. J. Biol. Chem. 290, 30204-30211 (2015)

11. Dusseaux, M. et al. Human MAIT cells are xenobioticresistant, tissue-targeted, CD $161 \mathrm{hi} \mathrm{IL-17-secreting}$ T cells. Blood 117, 1250-1259 (2011).

12. Fergusson, J. R. et al. CD161 int $C D 8+T$ cells: a novel population of highly functional, memory CD8+ T cells enriched within the gut. Mucosal Immunol. 9 401-413 (2016).

13. Gibbs, A. et al. MAIT cells reside in the female genital mucosa and are biased towards IL-17 and IL-22 production in response to bacterial stimulation. Mucosal Immunol. 10, 35-45 (2017).

14. Hinks, T. S. et al. Steroid-induced deficiency of mucosal-associated invariant T cells in the chronic obstructive pulmonary disease lung. implications for nontypeable Haemophilus influenzae infection. Am. J. Respir. Crit. Care Med. 194, 1208-1218 (2016).

15. Jeffery, H. C. et al. Biliary epithelium and liver B cells exposed to bacteria activate intrahepatic MAIT cells through MR1. J. Hepatol. 64, 1118-1127 (2016).

16. Magalhaes, I. et al. Mucosal-associated invariant T cell alterations in obese and type 2 diabetic patients. J. Clin. Invest. 125, 1752-1762 (2015). This is the first study to show that MAIT cells in blood and adipose tissue from obese and/or diabetic patients have an activated phenotype and exhibit a strong IL-17 profile.

17. Schmaler, M. et al. Modulation of bacterial metabolism by the microenvironment controls MAIT cell stimulation. Mucosal Immunol. 11, 1060-1070 (2018).

18. Serriari, N. E. et al. Innate mucosal-associated invariant T (MAIT) cells are activated in inflammatory bowel diseases. Clin. Exp. Immunol. 176, 266-274 (2014).

19. Sobkowiak, M. J. et al. Tissue-resident MAIT cell populations in human oral mucosa exhibit an activated profile and produce IL-17. Eur. J. Immunol. 49, 133-143 (2019).

20. Reantragoon, R. et al. Antigen-loaded MR1 tetramers define $T$ cell receptor heterogeneity in mucosalassociated invariant T cells. J. Exp. Med. $\mathbf{2 1 0}$ 2305-2320 (2013)

21. Gutierrez-Arcelus, M. et al. Lymphocyte innateness defined by transcriptional states reflects a balance between proliferation and effector functions. Nat. Commun. 10, 687 (2019).

22. Salou, M. et al. A common transcriptomic program acquired in the thymus defines tissue residency of MAIT and NKT subsets. J. Exp. Med. 216, 133-151 (2019).

23. Franciszkiewicz, K. et al. MHC class I-related molecule, $\mathrm{MR} 1$, and mucosal-associated invariant T cells. Immunol. Rev. 272, 120-138 (2016).

24. Rouxel, O. \& Lehuen, A. Mucosal-associated invariant $T$ cells in autoimmune and immune-mediated diseases. Immunol. Cell Biol. 96, 618-629 (2018).

25. Salou, M., Franciszkiewicz, K. \& Lantz, O. MAIT cells in infectious diseases. Curr. Opin. Immunol. 48, 7-14 (2017).

26. Keller, A. N., Corbett, A. J., Wubben, J. M McCluskey, J. \& Rossjohn, J. MAIT cells and MR1antigen recognition. Curr. Opin. Immunol. 46, 66-74 (2017).

27. Kurioka, A., Walker, L. J., Klenerman, P. \& Willberg, C. B. MAIT cells: new guardians of the liver. Clin. Transl Immunol. 5, e98 (2016).

28. Ussher, J. E., Willberg, C. B. \& Klenerman, P. MAIT cells and viruses. Immunol. Cell Biol. 96, 630-641 (2018).

29. Karamooz, E., Harriff, M. J. \& Lewinsohn, D. M. MR1-dependent antigen presentation. Semin. Cell Dev. Biol. 84, 58-64 (2018).

30. Gherardin, N. A., McCluskey, J., Rossjohn, J. \& Godfrey, D. I. The diverse family of MR1-restricted T cells. J. Immunol. 201, 2862-2871 (2018).

31. Meermeier, E. W., Harriff, M. J., Karamooz, E. \& Lewinsohn, D. M. MAIT cells and microbial immunity. Immunol. Cell Biol. 96, 607-617 (2018).

32. Magalhaes, I., Kiaf, B. \& Lehuen, A. iNKT and MAIT cell alterations in diabetes. Front. Immunol. 6, 341 (2015).

33. Le Bourhis, L. et al. MAIT cells detect and efficiently lyse bacterially-infected epithelial cells. PLOS Pathog. 9, e1003681 (2013).

34. Kurioka, A. et al. MAIT cells are licensed through granzyme exchange to kill bacterially sensitized targets. Mucosal Immunol. 8, 429-440 (2015).

35. Koay, H. F. et al. A three-stage intrathymic development pathway for the mucosal-associated invariant T cell lineage. Nat. Immunol. 17, 1300-1311 (2016).

36. Kwon, Y. S. et al. Mucosal-associated invariant $\mathrm{T}$ cells are numerically and functionally deficient in patients with mycobacterial infection and reflect disease activity. Tuberculosis (Edinb.) 95, 267-274 (2015).

37. Gade, P. et al. An IFN-gamma-stimulated ATF6-C/EBPbeta-signaling pathway critical for the expression of death associated protein kinase 1 and induction of autophagy. Proc. Natl Acad. Sci. USA 109 10316-10321 (2012).

38. Braverman, J. \& Stanley, S. A. Nitric oxide modulates macrophage responses to Mycobacterium tuberculosis infection through activation of HIF-1 alpha and repression of NF-kappaB. J. Immunol. 199 1805-1816 (2017).

39. MacMicking, J. D. et al. Identification of nitric oxide synthase as a protective locus against tuberculosis. Proc. Natl Acad. Sci. USA 94, 5243-5248 (1997).

40. Salerno-Goncalves, R. et al. Challenge of humans with wild-type Salmonella enterica serovar typhi elicits changes in the activation and homing characteristics of mucosal-associated invariant T cells. Front. Immunol. 8, 398 (2017)

41. Greene, J. M. et al. MR1-restricted mucosalassociated invariant T (MAIT) cells respond to mycobacterial vaccination and infection in nonhuman primates. Mucosal Immunol. 10, 802-813 (2017).

42. Grimaldi, D. et al. Specific MAIT cell behaviour among innate-like T lymphocytes in critically ill patients with severe infections. Intensive Care Med. 40, 192-201 (2014).

43. Chua, W. J. et al. Polyclonal mucosa-associated invariant $\mathrm{T}$ cells have unique innate functions in bacterial infection. Infect. Immun. 80, 3256-3267 (2012).

44. Cui, Y. et al. Mucosal-associated invariant T cell-rich congenic mouse strain allows functional evaluation. J. Clin. Invest. 125, 4171-4185 (2015).

45. Meierovics, A., Yankelevich, W. J. \& Cowley, S. C. MAIT cells are critical for optimal mucosal immune responses during in vivo pulmonary bacterial infection. Proc. Natl Acad. Sci. USA 110, E3119-E3128 (2013).

46. Meierovics, A. I. \& Cowley, S. C. MAIT cells promote inflammatory monocyte differentiation into dendritic cells during pulmonary intracellular infection. J. Exp. Med. 213, 2793-2809 (2016). This study shows that MAIT cells, by producing GM-CSF, induce monocyte polarization into monocyte-derived dendritic cells

47. Wang, $\mathrm{H}$. et al. MAIT cells protect against pulmonary Legionella longbeachae infection. Nat. Commun. 9 , 3350 (2018).

48. Chen, Z. et al. Mucosal-associated invariant T cell activation and accumulation after in vivo infection depends on microbial riboflavin synthesis and co-stimulatory signals. Mucosal Immunol. 10, 58-68 (2017).

49. Jesteadt, E. et al. Interleukin-18 is critical for mucosa-associated invariant T cell gamma interferon responses to francisella species in vitro but not in vivo. Infect. Immun. 86, e00117-18 (2018).

50. Ussher, J. E. et al. CD $161^{++} C D 8^{+}$T cells, including the MAIT cell subset, are specifically activated by IL-12+IL-18 in a TCR-independent manner. Eur. J. Immunol. 44, 195-203 (2014).

51. Barathan, M. et al. Peripheral loss of CD8 ${ }^{+} \mathrm{CD} 161^{++}$ TCRValpha7.2+ mucosal-associated invariant $\mathrm{T}$ cells in chronic hepatitis C virus-infected patients. Eur. J. Clin. Invest. 46, 170-180 (2016).

52. Billerbeck, E. et al. Analysis of CD161 expression on human $\mathrm{CD}^{+} \mathrm{T}$ cells defines a distinct functional subset with tissue-homing properties. Proc. Natl Acad. Sci. USA 107, 3006-3011 (2010).

53. Boeijen, L. L. et al. Mucosal-associated invariant T cells are more activated in chronic hepatitis B, but not depleted in blood: reversal by antiviral therapy. J. Infect. Dis. 216, 969-976 (2017).

54. Bolte, F. J. et al. Intra-hepatic depletion of mucosalassociated invariant $\mathrm{T}$ cells in hepatitis $\mathrm{C}$ virus-induced liver inflammation. Gastroenterology 153, 1392-1403 (2017).

55. Cosgrove, $\mathrm{C}$. et al. Early and nonreversible decrease of CD161++ /MAIT cells in HIV infection. Blood 121 , 951-961 (2013)

56. Eberhard, J. M. et al. Reduced CD $161^{+}$MAIT cell frequencies in HCV and HIV/HCV co-infection: is the liver the heart of the matter? J. Hepatol. 65 1261-1263 (2016).

57. Fernandez, C. S. et al. MAIT cells are depleted early but retain functional cytokine expression in HIV infection. Immunol. Cell Biol. 93, 177-188 (2015).

58. Hengst, J. et al. Nonreversible MAIT cell-dysfunction in chronic hepatitis $C$ virus infection despite successful interferon-free therapy. Eur. J. Immunol. 46 , 2204-2210 (2016).

59. Jo, J. et al. Toll-like receptor 8 agonist and bacteria trigger potent activation of innate immune cells in human liver. PLOS Pathog. 10, e1004210 (2014).

60. Leeansyah, E. et al. Activation, exhaustion, and persistent decline of the antimicrobial MR1-restricted MAIT-cell population in chronic HIV-1 infection. Blood 121, 1124-1135 (2013).

61. Leeansyah, E. et al. Arming of MAIT cell cytolytic antimicrobial activity is induced by IL-7 and defective in HIV-1 infection. PLOS Pathog. 11, e1005072 (2015).

62. Loh, L. et al. Human mucosal-associated invariant $T$ cells contribute to antiviral influenza immunity via IL-18-dependent activation. Proc. Natl Acad. Sci. USA 113, 10133-10138 (2016)

63. Paquin-Proulx, D. et al. MAIT cells are reduced in frequency and functionally impaired in human T lymphotropic virus type 1 infection: potential clinical implications. PLOS ONE 12, e0175345 (2017).

64. Sereti, I. et al. IL-7 administration drives T cell-cycle entry and expansion in HIV-1 infection. Blood 113, 6304-6314 (2009).

65. Sortino, O. et al. IL-7 treatment supports CD8 mucosa-associated invariant T cell restoration in HIV1 -infected patients on antiretroviral therapy. AIDS 32 825-828 (2018).

66. van Wilgenburg, B. et al. MAIT cells are activated during human viral infections. Nat. Commun. 7 11653 (2016)

This is the first study to show MAIT cell activation upon virus infection in a manner that is TCR independent but dependent on IL-18, IL-12 and IL-15.

67. Wilgenburg, B. V. et al. MAIT cells contribute to protection against lethal influenza infection in vivo. Nat. Commun 9, 4706 (2018).

68. Yong, Y. K. et al. Decrease of CD69 levels on TCR Valpha7. $2^{+} \mathrm{CD}^{+}$innate-like lymphocytes is associated with impaired cytotoxic functions in chronic hepatitis $\mathrm{B}$ virus-infected patients. Innate Immun. $\mathbf{2 3}$ 459-467 (2017). 
69. Hegde, P. et al. Mucosal-associated invariant T cells are a profibrogenic immune cell population in the liver. Nat. Commun. 9, 2146 (2018)

This study shows that MAIT cells are profibrogenic in the liver by promoting macrophage inflammatory properties and myofibroblast activation.

70. Rouxel, O. et al. Cytotoxic and regulatory roles of mucosal-associated invariant T cells in type 1 diabetes. Nat. Immunol. 18, 1321-1331 (2017). The study is the first to describe MAIT cell alterations in patients with type 1 diabetes and the regulatory role of these cells through maintaining gut integrity.

71. Salou, M. et al. Neuropathologic, phenotypic and functional analyses of mucosal associated invariant T cells in multiple sclerosis. Clin. Immunol. 166-167, 1-11 (2016)

72. Braudeau, C. et al. Persistent deficiency of circulating mucosal-associated invariant T (MAIT) cells in ANCAassociated vasculitis. J. Autoimmun. 70, 73-79 (2016).

73. Carolan, E. et al. Altered distribution and increased IL-17 production by mucosal-associated invariant T cells in adult and childhood obesity. J. Immunol. 194, 5775-5780 (2015).

74. Dunne, M. R. et al. Persistent changes in circulating and intestinal gammadelta $T$ cell subsets, invariant natural killer T cells and mucosal-associated invariant $\mathrm{T}$ cells in children and adults with coeliac disease. PLOS ONE 8, e76008 (2013).

75. Fazekas, B. et al. Alterations in circulating lymphoid cell populations in systemic small vessel vasculitis are non-specific manifestations of renal injury. Clin. Exp. Immunol. 191, 180-188 (2018)

76. Gerart, S. et al. Human iNKT and MAIT cells exhibit a PLZF-dependent proapoptotic propensity that is counterbalanced by XIAP. Blood 121, 614-623 (2013).

77. Gracey, E. et al. IL-7 primes IL-17 in mucosalassociated invariant T (MAIT) cells, which contribute to the Th17-axis in ankylosing spondylitis. Ann. Rheum. Dis. 75, 2124-2132 (2016)

78. Guggino, G. et al. IL-17 polarization of MAIT cells is derived from the activation of two different pathways. Eur. J. Immunol. 47, 2002-2003 (2017).

79. Haga, K. et al. MAIT cells are activated and accumulated in the inflamed mucosa of ulcerative colitis. J. Gastroenterol. Hepatol. 31, 965-972 (2016).

80. Hayashi, E. et al. Involvement of mucosal-associated invariant T cells in ankylosing spondylitis. J. Rheumato 43, 1695-1703 (2016)

81. Hiejima, E. et al. Reduced numbers and proapoptotic features of mucosal-associated invariant T cells as a characteristic finding in patients with inflammatory bowel disease. Inflamm. Bowel Dis. 21, 1529-1540 (2015)

82. Renand, A. et al. Immune alterations in patients with type 1 autoimmune hepatitis persist upon standard immunosuppressive treatment. Hepatol. Commun. 2 , 968-981 (2018)

83. Riva, A. et al. Mucosa-associated invariant T cells link intestinal immunity with antibacterial immune defects in alcoholic liver disease. Gut 67, 918-930 (2018)

This study shows that in patients with alcoholic liver disease, MAIT cell dysfunction is associated with gut dysbiosis.

84. Toussirot, E., Laheurte, C., Gaugler, B., Gabriel, D. \& Saas, P. Increased IL-22- and IL-17A-producing mucosal-associated invariant $\mathrm{T}$ cells in the peripheral blood of patients with ankylosing spondylitis. Front. Immunol. 9, 1610 (2018).

85. von Seth, E. et al. Primary sclerosing cholangitis leads to dysfunction and loss of MAIT cells. Eur. J. Immunol. 48, 1997-2004 (2018)

86. Wang, J. J., Macardle, C., Weedon, H., Beroukas, D. \& Banovic, T. Mucosal-associated invariant T cells are reduced and functionally immature in the peripheral blood of primary Sjogren's syndrome patients. Eur. J. Immunol. 46, 2444-2453 (2016).

87. Bottcher, K et al. MAIT cells are chronically activated in patients with autoimmune liver disease and promote profibrogenic hepatic stellate cell activation. Hepatology 68, 172-186 (2018)

88. Chiba, A. et al. Activation status of mucosal-associated invariant $\mathrm{T}$ cells reflects disease activity and pathology of systemic lupus erythematosus. Arthritis Res. Ther. 19, 58 (2017)

89. Cho, Y. N. et al. Mucosal-associated invariant T cell deficiency in systemic lupus erythematosus. J. Immunol. 193, 3891-3901 (2014).
90. Hinks, T. S. et al. Innate and adaptive T cells in asthmatic patients: relationship to severity and disease mechanisms. J. Allergy Clin. Immunol. 136, 323-333 (2015)

91. Kim, M. et al. TNFalpha and IL- 1 beta in the synovial fluid facilitate mucosal-associated invariant T (MAIT) cell migration. Cytokine 99, 91-98 (2017).

92. Lezmi, G. et al. Circulating IL-17-producing mucosalassociated invariant T cells (MAIT) are associated with symptoms in children with asthma. Clin. Immunol. 188, 7-11 (2018).

93. Li, Y. et al. Mucosal-associated invariant T cells improve nonalcoholic fatty liver disease through regulating macrophage polarization. Front. Immuno 9, 1994 (2018).

94. Touch, S. et al. Mucosal-associated invariant T (MAIT) cells are depleted and prone to apoptosis in cardiometabolic disorders. FASEB J. 32 fj201800052RR (2018)

95. Miyazaki, Y., Miyake, S., Chiba, A., Lantz, O. \& Yamamura, T. Mucosal-associated invariant T cells regulate Th1 response in multiple sclerosis. Int Immunol. 23, 529-535 (2011).

96. Illes, Z., Shimamura, M., Newcombe, J., Oka, N. \& Yamamura, T. Accumulation of Valpha7.2-Jalpha33 invariant $\mathrm{T}$ cells in human autoimmune inflammatory lesions in the nervous system. Int. Immunol. 16, 223-230 (2004)

97. Li, J. et al. The frequency of mucosal-associated invariant T cells is selectively increased in dermatitis herpetiformis. Australas. J. Dermatol. 58, 200-204 (2017).

98. Teunissen, M. B. M. et al. The IL-17A-producing $\mathrm{CD} 8^{+} \mathrm{T}$ cell population in psoriatic lesional skin comprises mucosa-associated invariant T cells and conventional T cells. J. Invest. Dermatol. 134 2898-2907 (2014).

99. Willing, A. et al. CD8 ${ }^{+}$MAIT cells infiltrate into the CNS and alterations in their blood frequencies correlate with IL-18 serum levels in multiple sclerosis. Eur. J. Immunol. 44, 3119-3128 (2014).

100. Abrahamsson, S. V. et al. Non-myeloablative autologous haematopoietic stem cell transplantation expands regulatory cells and depletes IL-17 producing mucosal-associated invariant T cells in multiple sclerosis. Brain 136, 2888-2903 (2013).

101. Nicoletti, F. et al. Increased serum levels of interleukin-18 in patients with multiple sclerosis. Neurology 57, 342-344 (2001)

102. Ifergan, I. et al. Central nervous system recruitmen of effector memory $C D 8^{+} \mathrm{T}$ lymphocytes during neuroinflammation is dependent on alpha4 integrin. Brain 134, 3560-3577 (2011).

103. Ito, T., Carson, W. F.t., Cavassani, K. A., Connett, J. M $\&$ Kunkel, S. L. CCR6 as a mediator of immunity in the lung and gut. Exp. Cell Res. 317, 613-619 (2011).

104. Ganz, T. Defensins: antimicrobial peptides of innate immunity. Nat. Rev. Immunol. 3, 710-720 (2003).

105. Miani, M. et al. Gut microbiota-stimulated innate lymphoid cells support beta-defensin 14 expression in pancreatic endocrine cells, preventing autoimmune diabetes. Cell Metab. 28, 557-572 (2018).

106. Godfrey, D. I., Uldrich, A. P., McCluskey, J., Rossjohn, J. $\S$ Moody, D. B. The burgeoning family of unconventiona T cells. Nat. Immunol. 16, 1114-1123 (2015).

107. Novak, J., Dobrovolny, J., Novakova, L. \& Kozak, T. The decrease in number and change in phenotype of mucosal-associated invariant T cells in the elderly and differences in men and women of reproductive age. Scand. J. Immunol. 80, 271-275 (2014).

108. Walker, L. J., Tharmalingam, H. \& Klenerman, P. The rise and fall of MAIT cells with age. Scand. J. Immunol. 80, 462-463 (2014).

109. Hanson, E. D. et al. Exercise increases mucosalassociated invariant $\mathrm{T}$ cell cytokine expression but not activation or homing markers. Med. Sci. Sports Exerc. 51, 379-388 (2019).

110. Keller A. N. et al. Drugs and drug-like molecules can modulate the function of mucosal-associated invariant T cells. Nat. Immunol. 18, 402-411 (2017).

111. Annibali, V. et al. CD $161^{\text {high }} \mathrm{CD} 8{ }^{+}$T cells bear pathogenetic potential in multiple sclerosis. Brain 134, 542-554 (2011).

112. Hinks, T. S. Reduced numbers and proapoptotic features of mucosal-associated invariant $T$ cells as a characteristic finding in patients with inflammatory bowel disease. Inflamm. Bowel Dis. 21, E30 (2015)

113. Dias, J., Leeansyah, E. \& Sandberg, J. K. Multiple layers of heterogeneity and subset diversity in human MAIT cell responses to distinct microorganisms and to innate cytokines. Proc. Natl Acad. Sci. USA 114, E5434-E5443 (2017).
114. Dias, J. et al. The CD4-CD8- MAIT cell subpopulation is a functionally distinct subset developmentally related to the main CD8 ${ }^{+}$MAIT cell pool. Proc. Natl Acad. Sci. USA 115, E11513-E11522 (2018).

115. Rahimpour, A. et al. Identification of phenotypically and functionally heterogeneous mouse mucosalassociated invariant T cells using MR1 tetramers. J. Exp. Med. 212, 1095-1108 (2015). This is the first study to provide exhaustive MAIT cell phenotypes and cytokine production in different tissues of $\mathrm{C} 57 \mathrm{BL} / 6$ and BALB/c mice

116. Marwaha, A. K., Leung, N. J., McMurchy, A. N. $\&$ Levings, M. K. $\mathrm{T}_{\mathrm{H}} 17$ cells in autoimmunity and immunodeficiency: protective or pathogenic? Front. Immunol. 3, 129 (2012).

117. Chiba, A. et al. Mucosal-associated invariant T cells promote inflammation and exacerbate disease in murine models of arthritis. Arthritis Rheum. 64 153-161 (2012)

118. Willing, A., Jager, J., Reinhardt, S., Kursawe, N. $\delta$ Friese, M. A. Production of IL-17 by MAIT cells is increased in multiple sclerosis and is associated with IL-7 receptor expression. J. Immunol. 200, 974-982 (2018).

119. Ciccia, F. et al. Type 3 innate lymphoid cells producing IL-17 and IL-22 are expanded in the gut, in the peripheral blood, synovial fluid and bone marrow of patients with ankylosing spondylitis. Ann. Rheum. Dis. 74, 1739-1747 (2015)

120. Rihl, M. et al. Identification of interleukin- 7 as a candidate disease mediator in spondylarthritis. Arthritis Rheum. 58, 3430-3435 (2008).

121. International Genetics of Ankylosing Spondylitis Consortium (IGAS). Identification of multiple risk variants for ankylosing spondylitis through highdensity genotyping of immune-related loci. Nat. Genet. 45, 730-738 (2013)

122. Fabbrini, E. et al. Association between specific adipose tissue $\mathrm{CD}^{+} \mathrm{T}$ cell populations and insulin resistance in obese individuals. Gastroenterology 145, 366-374 (2013).

123. Zuniga, L. A. et al. IL-17 regulates adipogenesis, glucose homeostasis, and obesity. J. Immunol. 185 , 6947-6959 (2010).

124. Kuric, E. et al. No evidence for presence of mucosalassociated invariant $\mathrm{T}$ cells in the insulitic lesions in patients recently diagnosed with type 1 diabetes. Am. J. Pathol. 188, 1744-1748 (2018).

125. Ruijing, X. et al. Ja33+ MAIT cells play a protective role in TNBS induced intestinal inflammation. Hepatogastroenterology 59, 762-767 (2012).

126. Croxford, J. L., Miyake, S., Huang, Y. Y., Shimamura, M. \& Yamamura, T. Invariant $\mathrm{V}_{\alpha} 19 \mathrm{i}$ T cells regulate autoimmune inflammation. Nat. Immunol. 7 987-994 (2006)

This is the first report to describe MAIT cell inhibition of autoimmune disease in the context of experimental autoimmune encephalomyelitis.

127. Song, F. et al. Expression of the neutrophil chemokine $\mathrm{KC}$ in the colon of mice with enterocolitis and by intestinal epithelial cell lines: effects of flora and proinflammatory cytokines. J. Immunol. 162 2275-2280 (1999).

128. Kaneko, M., Akiyama, Y., Takimoto, H. \& Kumazawa, Y Mechanism of up-regulation of immunoglobulin A production in the intestine of mice unresponsive to lipopolysaccharide. Immunology 116, 64-70 (2005).

129. Chandra, S. et al. Development of asthma in inner-city children: possible roles of MAIT cells and variation in the home environment. J. Immunol. 200, 1995-2003 (2018).

130. Bach, J. F. The hygiene hypothesis in autoimmunity: the role of pathogens and commensals. Nat. Rev. Immunol. 18, 105-120 (2018).

131. Shimamura, M. et al. Regulation of immunological disorders by invariant Valpha19-Jalpha33 TCRbearing cells. Immunobiology 216, 374-378 (2011).

132. Harley, I. T. et al. IL-17 signaling accelerates the progression of nonalcoholic fatty liver disease in mice. Hepatology 59, 1830-1839 (2014).

133. Marra, F. \& Lotersztajn, S. Pathophysiology of NASH perspectives for a targeted treatment. Curr. Pharm. Des. 19, 5250-5269 (2013).

134. Ling, L. et al. Circulating and tumor-infiltrating mucosal associated invariant T (MAIT) cells in colorectal cancer patients. Sci. Rep. 6, 20358 (2016)

135. Zabijak, L. et al. Increased tumor infiltration by mucosal-associated invariant $T$ cells correlates with poor survival in colorectal cancer patients. Cancer Immunol. Immunother. 64, 1601-1608 (2015).

136. Won, E. J. et al. Clinical relevance of circulating mucosal-associated invariant T cell levels and their 
anti-cancer activity in patients with mucosalassociated cancer. Oncotarget 7, 76274-76290 (2016).

137. Duan, M. et al. Activated and exhausted MAIT cells foster disease progression and indicate poor outcome in hepatocellular carcinoma. Clin. Cancer Res. 25 3304-3316 (2019).

This study describes major MAIT cell alterations in hepatocellular carcinoma and the poor clinical outcome associated with high tumour MAIT cell infiltration

138. Sundstrom, P. et al. Human mucosa-associated invariant $\mathrm{T}$ cells accumulate in colon adenocarcinomas but produce reduced amounts of IFN-gamma. J. Immunol. 195, 3472-3481 (2015).

139. Shaler, C. R. et al. Mucosa-associated invariant T cells infiltrate hepatic metastases in patients with colorectal carcinoma but are rendered dysfunctional within and adjacent to tumor microenvironment. Cancer Immunol. Immunother. 66, 1563-1575 (2017).

140. Kawaguchi, K et al. Influence of post-transplant mucosal-associated invariant $\mathrm{T}$ cell recovery on the development of acute graft-versus-host disease in allogeneic bone marrow transplantation. Int. J. Hematol. 108, 66-75 (2018)

141. Bhattacharyya, A. et al. Graft-derived reconstitution of mucosal-associated invariant T cells after allogeneic hematopoietic cell transplantation. Biol. Blood Marrow Transplant. 24, 242-251 (2018).

142. Varelias, A. et al. Recipient mucosal-associated invariant T cells control GVHD within the colon. J. Clin Invest. 128, 1919-1936 (2018).

143. Mondot, S., Boudinot, P. \& Lantz, O. MAIT, MR1, microbes and riboflavin: a paradigm for the co-evolution of invariant TCRs and restricting $\mathrm{MHCl}$ like molecules? Immunogenetics 68, 537-548 (2016).

144. Garner, L. C., Klenerman, P. \& Provine, N. M. Insights into mucosal-associated invariant $\mathrm{T}$ cell biology from studies of invariant natural killer T cells. Front. Immunol. 9, 1478 (2018).

145. Seino, K. \& Taniguchi, M. Functionally distinct NKT cell subsets and subtypes. J. Exp. Med. 202, 1623-1626 (2005).
146. Kain, L. et al. The identification of the endogenous ligands of natural killer $\mathrm{T}$ cells reveals the presence of mammalian alpha-linked glycosylceramides. Immunity 41, 543-554 (2014)

147. Tastan, C. et al. Tuning of human MAIT cell activation by commensal bacteria species and MR1-dependent T cell presentation. Mucosal Immunol. 11, 1591-1605 (2018).

148. Lepore, M. et al. Functionally diverse human T cells recognize non-microbial antigens presented by MR1 eLife 6, e24476 (2017).

149. Opazo, M. C. et al. Intestinal microbiota influences non-intestinal related autoimmune diseases. Front. Microbiol. 9, 432 (2018).

150. Kamada, N., Seo, S. U., Chen, G. Y. \& Nunez, G. Role of the gut microbiota in immunity and inflammatory disease. Nat. Rev. Immunol. 13 321-335 (2013)

151. Kho, Z. Y. \& Lal, S. K. The human gut microbiome a potential controller of wellness and disease. Front. Microbiol. 9, 1835 (2018).

152. Voillet, V. et al. Human MAIT cells exit peripheral tissues and recirculate via lymph in steady state conditions. JCl Insight 3, 98487 (2018).

153. Sugimoto, C. et al. Mucosal-associated invariant $\mathrm{T}$ cell is a potential marker to distinguish fibromyalgia syndrome from arthritis. PLOS ONE 10, e0121124 (2015).

154. Gherardin, N. A. et al. Human blood MAIT cell subsets defined using MR1 tetramers. Immunol. Cell Biol. 96 , 507-525 (2018)

155. Nicol, B et al. An intermediate level of CD161 expression defines a novel activated, inflammatory, and pathogenic subset of $C D 8^{+} \mathrm{T}$ cells involved in multiple sclerosis. J. Autoimmun. 88, 61-74 (2018).

156. Cheuk, S. et al. CD49a expression defines tissueresident $\mathrm{CD} 8{ }^{+} \mathrm{T}$ cells poised for cytotoxic function in human skin. Immunity 46, 287-300 (2017).

157. Jiang, J. et al. Mucosal-associated invariant T cells from patients with tuberculosis exhibit impaired immune response. J. Infect. 72, 338-352 (2016).

158. Cliff, J. M. et al. Cellular immune function in myalgic encephalomyelitis/chronic fatigue syndrome (ME/CFS) Front. Immunol. 10, 796 (2019).
159. Ishimori, A. et al. Circulating activated innate lymphoid cells and mucosal-associated invariant $\mathrm{T}$ cells are associated with airflow limitation in patients with asthma. Allergol. Int. 66, 302-309 (2017).

160. Peterfalvi, A. et al. Invariant Va7.2-Ja33 TCR is expressed in human kidney and brain tumors indicating infiltration by mucosal-associated invariant T (MAIT) cells. Int. Immunol. 20, 1517-1525 (2008).

161. Zumwalde, N. A., Haag, J. D., Gould, M. N. \& Gumperz, J. E. Mucosal associated invariant T cells from human breast ducts mediate a Th17-skewed response to bacterially exposed breast carcinoma cells. Breast Cancer Res. 20, 111 (2018).

\section{Acknowledgements}

The authors are grateful to $U$. Rogner for critical reading of the manuscript. This work was supported by grants from INSERM, CNRS, Laboratoire d'Excellence consortium Inflamex (grant number ANR-11-IDEX-0005-02) and the Fondation pour la Recherche Médicale (FRM grant numbers DEQ20140329520, to A.L., and DEQ20150331726, to S.L.), EFSD/JDRF/Lilly and EFSD/Lilly (to A.L. and A.T.), Fondation Francophone pour la recherche sur le Diabète (to A.L.), an Aide aux Jeunes Diabétiques fellowship to I.N., and Agence Nationale de la Recherche (ANR OBEMAIT, Provide and Diab1MAIT grants to A.L.).

\section{Author contributions}

All authors contributed to writing the review. A.T. and I.N. contributed equally.

Competing interests

The authors declare no competing interests.

Publisher's note

Springer Nature remains neutral with regard to jurisdictional claims in published maps and institutional affiliations.

\section{Reviewer information}

Nature Reviews Immunology thanks P. Klenerman and J. Sandberg for their contribution to the peer review of this work. 